NIPER-535

Distribution Category UC-122

NIPER- -535

THE EFFECT OF ALKALINE AGENTS ON RETENTION OF EOR CHEMICALS

DE91 002246

By

Philip B. Lorenz

July 1991

Work Performed Under Cooperative Agreement No. FC22-83FE60149

\author{
Prepared for \\ U.S. Department of Energy \\ Assistant Secretary for Fossil Energy
}

Thomas B. Reid, Project Manager

Bartlesville Project Office

P. O. Box 1398

Bartlesville, OK 74005

\author{
Prepared by \\ IIT Research Institute \\ National Institute for Petroleum and Energy Research \\ P. O. Box 2128 \\ Bartlesville, OK 74005
}




\section{TABLE OF CONTENTS}

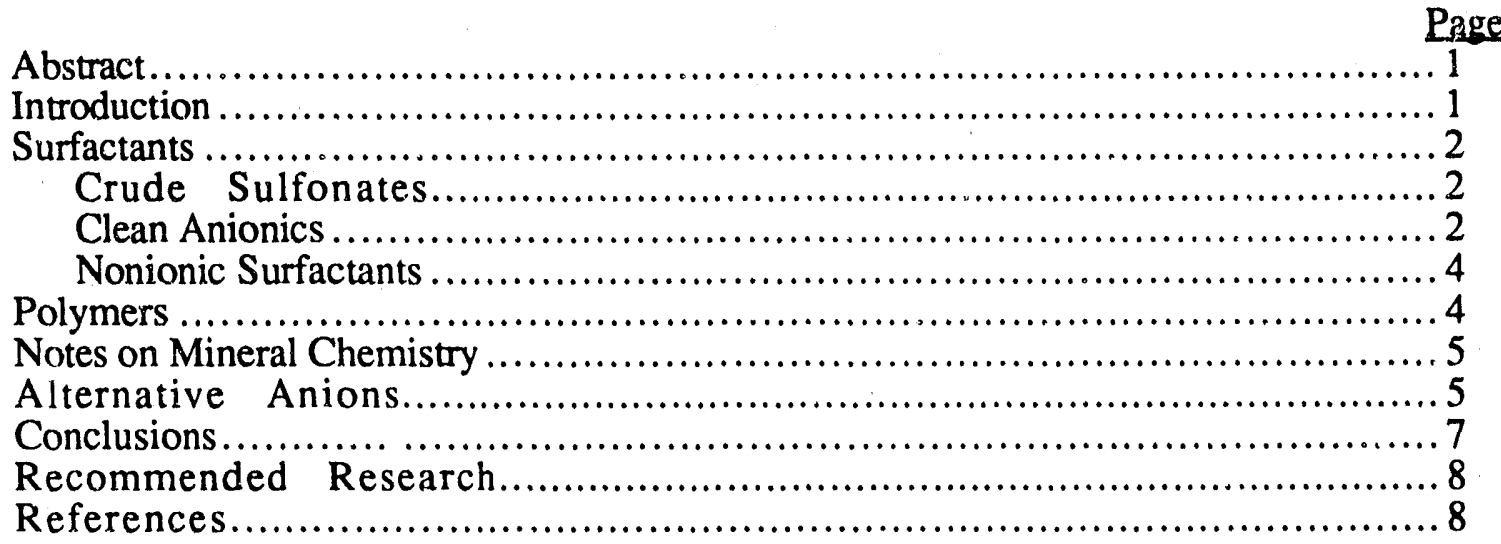

TABLES

1. Adsorption ( $\mu$ eq/g) of Petrostep B-100 (0.1 wt, \%) on Berea sand ............... 15

2. Effect of various alkalis on surfactant retention and effluent hardness in flowing experiments through Berea core.......................................... 16

3. Adsorption ( $\mu \mathrm{eq} / \mathrm{g})$ at $\mathrm{CMC}$ of cationic and anionic surfactants on kaolinite ........ 17

4. Adsorption of sodium dodecylbenzene sulfonate on sodium kaolinite at $30^{\circ} \mathrm{C} \ldots \ldots 18$

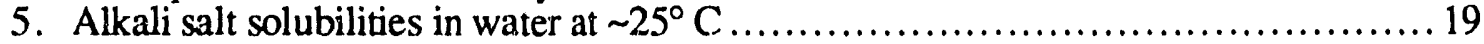

6 Effect of metasilicate and orthophosphate on adsorption at two pH levels............. 20

\section{ILLUSTRATIONS}

1. Effect of $\mathrm{pH}$ on the abstraction of Mahogany AA sulfonate (initial concentration $12.6 \mathrm{~g} / \mathrm{dm}^{3}$ active) on Bedford limestone...................21

2. Effect of the $\mathrm{pH}$ of a carbonate brine on adsorption of a petroleum sulfonate

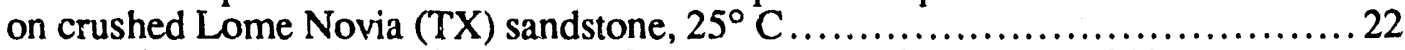

3. Adsorption and depletion isotherms of a petroleum sulfonate (MW 390) on ground Berea sandstone $\left(1.5 \mathrm{~m}^{2} / \mathrm{g}\right)$.

4. Adsorption of sodium dodecylbenzene sulfonate on kaolinite at $30^{\circ} \mathrm{C}$..................24

5. Adsorption of sodium sulfonates on alumina..................................... 25

6. Adsorption of sodium dodecylbenzene sulfonate on kaolinite .......................26

7. Adsorption of sodium dodecylsulfonate $\left(2.06 \mathrm{~m} \mathrm{~mol} / \mathrm{dm}^{3}\right)$ on sodium kaolinite

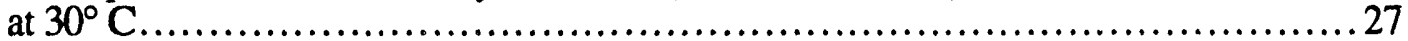

8. Abstraction isotherms for sodium dodecylbenzene sulfonate (recrystallized isomeric mixture) on sodium kaolinite ............................. 28

9. Change in abstraction and system $\mathrm{pH}$ in a series of $\mathrm{pH}$-adjusted $50 \%$ dilutions of sodium dodecylbenzene sulfonate (recrystallized isomeric mixture)

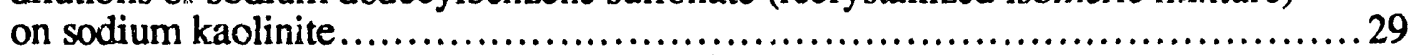

10. Effect of $\mathrm{pH}$ on adsorption of monoisomeric sodium dodecylbenzene sulfonate (benzene on fourth carbon in chain) on homoionic sodium kaolinite ...... 30

11. Effect of $\mathrm{pH}$ on $\mathrm{CMC}$ of isomerically pure sdium alklylbenzene sulfonates. $3 \varnothing \mathrm{C}_{10}=$ benzene on third carbor of decyl chain; $4 \varnothing \mathrm{C}_{12}=$ benzene on fourth carbon of dodecyl chain.............................................. 31

12. Effect of $\mathrm{pH}$ on adsorption of Igepals on Kaolinite................................. 32

13. Adsorption of ethoxylated nonylphenol C9Ø(EO)9 on precipitated silica $\left(62 \mathrm{~m}^{2} / \mathrm{g}\right)$ and on silica treated with trimethyl chlorosilane. 
14. The effect of cloud point on adsorption of Igepal CO-630 on kaolinite .............34 34

15. Transient interfacial tension of deacidified Wilmington (CA) crude oil and $0.1 \%$ Neodol 25-9.

16. Adsorption of polyacrylamide $\left(\mathrm{MW} \simeq 8 \times 10^{6}\right.$ dalton) on sodium kaolinite (lateral surface area $5 \mathrm{~m}^{2} / \mathrm{g}$ ) in the presence of $0.34 \mathrm{M} \mathrm{NaCl}$; polymer>100 ppm.... 36

17. Adsorption isotherms for aminated polyacrylamide (10 mol- $\%$ positive charge) on silica (Biosil) ....

18. Adsorption of polyacrylamide $\left(\mathrm{MW}=7.5 \times 10^{6}\right.$ dalton) on sand $(0.1 \mathrm{~m} 2 / \mathrm{g})$, from a solution at $150 \mathrm{ppm}$ in $0.34 \mathrm{M} \mathrm{NaCl}$ at $\mathrm{pH} 7$.

19. Adsorption of polyacrylamide (MW $1.2 \times 10^{6}$ dalton $<1 \%$ hydrolyzed) on sodium kaolinite (lateral surface area $8.3 \mathrm{~m}^{2} / \mathrm{g}$ ) at $24^{\circ}$. .

20. Adsorption of unhydrolyzed polyacrylamide on sodium kaolinite $\left(9.8 \mathrm{~m}^{2} / \mathrm{g}\right) \ldots \ldots . .40$

21. Adsorption isotherms for sodium $n$-decylbenzene sulfonate on various minerals. . .41

22. Equilibrium $\mathrm{pH}$ obtained by contacting sodium kaolinite with $\mathrm{pH}$-adjusted solutions of sodium chloride

23. Effluent profiles in a dilute surfactant flood enhanced by sodium carbonate (no oil) in Berea cores ( 2 in $\times 1 \mathrm{ft}$ ) 43

24. Qualitative interpretation of silicate ion structure equilibria...................... 44

25. Adsorption as a function of $\mathrm{pH}$ with various alkalis.................................. 45

26. The effect of partly-hydrolyzed polyacrylamide, $40 \mathrm{ppm}$, on the adsorption isotherms for $n+3$ silicate of figure 25 .

27. $\mathrm{pH}$ values for silicate solutions of different concentrations and silicate ratios......4 47

28. Domains of solubility, colloidal dispersion, and insolubility for silicates............. 48 


\title{
THE EFFECT OH ALKALINE AGENTS ON RETENTION OF EOR CHEMICALS
}

\author{
By Philip B. Lorenz
}

\begin{abstract}
This report summarizes a literature survey on how alkaline agents reduce losses of surfactants and polymers in oil recovery by chemical injection. Data are reviewed for crude sulfonates, clean anionic surfactants, nonionic surfactants, and anionic and nonionic polymers. The role of mineral chemistry is briefly described. Specific effects of various alkaline anions are discussed. Investigations needed to improve the design of alkaline-surfactant-polymer floods are suggested.
\end{abstract}

\section{INTRODUCTION}

The Department of Energy has authorized research at NIPER in alkaline-surfactant-polymer (ASP) flooding for enhanced oil recovery (EOR), as part of the Department's goal to maximize the economic producibility of the domestic oil resource. ASP flooding shows promise of being costeffective because alkali, in addition to reinforcing the activity of surfactants, reduces the depletion of surfactant and polymer by retention in the reservoir. The effectiveness of alkaline chemicals for this purpose varies widely with rock mineralogy and brine composition. In particular, effectiveness tends to increase with increasing $\mathrm{pH}$. However, for most reservoirs, reaction with minerals is a serious problem for strong alkalis, and a flood needs to be operated at the lowest effective $\mathrm{pH}$, about 10 . Since the loss of chemicals by reaction or retention is a very important factor in the economics of ASP flooding, it is desirable to have complete information for optimizing the process.

For anionic chemicals - sulfonates and hydrolyzed polyacrylamides -- the reduction of adsorption is most pronounced in the low $\mathrm{pH}$ range where the solid surface is positively charged. This is the result of the electrostatic component of adsorption. In the high-pH range, where the surface becomes negatively charged, $\mathrm{pH}$ usually has a less dramatic, but still significant influence on adsorption.

It is important to remember that adsorption is only one form of retention. Multivalent cations form precipitates with sulfonates. The combination of adsorption and precipitation is referred to as abstraction. Both factors are reduced by alkalis, which compete with sulfonates for multivalent cations in solution or in exchange sites. Partitioning of surfactants into residual oil is another major cause of retention, but no study of how this is affected by alkalinity has been reported. Partitioning should be increased if the addition of an alkaline agent increases the ionic strength or if natural surfactants generated from oil by an alkali lower the optinıal salinity. For polymers, mechanical entrapment is often more important than adsorption'. Again, no direct investigations of the effect of 
$\mathrm{pH}$ have been reported. Mechanical entrapment probably will be affected by wettability, ionization, and hydrolysis, which can be altered by alkalinity; however, changes in these parameters between pH 6 and 10 are likely to be small. V'ith polymers, retention is not always deleterious. Permeability reduction by polymer adsorption or entrapment has beeil shown to be a more important effect of polymers in some cases than a simple viscosity increase. ${ }^{2}$

\section{SURFACTANTS}

\section{Crude Sulfonates}

The benefits of alkalis added to surfactants as sacrificial agents have been recognized qualitatively. ${ }^{3-5}$ Qualitatively, figure $1^{6}$ shows an adsorption-pH curve of typical shape, with a steep decline in adsorption between $\mathrm{pH} 8$ and 9 . Douglas 7 presents similar results for a petroleum sulfonate on alurnina, for which the decline leveled off at about $\mathrm{pH} 6$. The curve of figure 2,8 from results on a field core, lies in a higher $\mathrm{pH}$ range and has a higher minimum. This probably reflects specific properties of the carbonate rock. Some NIPER results ${ }^{9}$ with a carbonate alkali and Petrostep ${ }^{\mathrm{TM}}$ surfactant on Wilmington (CA) sand are similar. In other NIPER work, ${ }^{10}$ weak alkaline agents effected only a marginal reduction of adsorption of Petrostep products on crushed Berea sand (table 1). On the other hand, Krumrine et al. ${ }^{11,12}$ observed a markedly reduced adsorption of Petrostep on Berea by proper selection of the alkaline agents (table 2). Several investigations by Somasundaran $6,13-14$ illustrate how variable the results can be. Figure $3^{13}$ shows the dependence on surfactant concentration and previous history. In work on mahogany sulfonate and Berea, ${ }^{14}$ an increase in initial pH from 5 to 11 reduced adsorption only from 1.0 to $0.6 \mathrm{mg} / \mathrm{g}$; however, the equilibrium $\mathrm{pH}$ values were very similar, 8.3 and 8.8 , presumably because of the effect of carbonate minerals. In one study ${ }^{6}$ with mahogany sulfonate on agricultural limestone, the adsorption increased fourfold when $\mathrm{pH}$ was increased from 8 to 10 , probably because of a major change in the solid surface. It is evident that meaningful results can be obtained only by controlled experiments.

\section{Clean Anionics}

The characteristic shape of adsorption-pH curves -- a rapid decline in the acid range and a slow decline in the alkaline range -- is shown in figure 4 for sodium dodecylbenzene sulfonate as measured in three laboratories. The variability of the results is seen even in systems with relative simple chemical composition. It is plausible to assume that the values of Baviere et al. ${ }^{15}$ are higher than those of Somasundaran ${ }^{16}$ because of higher salinity and isomeric purity, both of which have been found to increase adsorption. ${ }^{6,17}$ The large divergence of Wade and Schechter's results ${ }^{18}$ has no obvious explanation.

The point of zero charge ( $\mathrm{pZC}$ ) was reported for the latter experiments ${ }^{18}$ and corresponds roughly with the major change of slope in the adsorption curve. In figure 5 , the decline of 
adsorption observed by Schechter and $\mathrm{Wade}^{19}$ at higher $\mathrm{pH}$ corresponds with the higher pZC of alumina. The influence of electrostatic effects is confirmed in table 3,20 which shows that the cationic surfactants behave in a manner converse to that of anionics. Unfortunately, not all the data conform to this neat pattern, as seen in the results of Somasundaran and Fuerstenau ${ }^{21}$ in figure 5.

Even, figure 6, with results all from the same laboratory, 6,17,22-24 shows some unexpected variations. Adsorption appears to be higher on homoionic kaolinite than natural; but the opposite effect was observed by Yang et al. ${ }^{25}$ Adsorption should be increased by the presence of divalent cations in exchange positions in natural clay. From table 4 , which represents very systematic studies, we can conclude that the effect of $\mathrm{pH}$ is smaller at high salinity and the effect of salinity is larger at high $\mathrm{pH}$. This is also illustrated in figure 7.26

The principal conclusions to be drawn from work on clean anionics are as follows:

(1) An increase in $\mathrm{pH}$ from 6 to 10 causes a modest decrease in adsorption.

(2) The benefit of alkali in reducing adsorption is greater at low salinity.

(3) The variations with surfactant and solid indicate that the benefit of alkali can be enhanced by tailoring the surfactant to the reservoir, but systematic data are needed to make this possible.

(4) It is important in experimental studies to maintain careful control of conditions such as the preparation of the surface, path of approach to equilibrium, selection of position along the adsorption isotherm, and solid/liquid ratio.

Some observations of additional interest can be made:

(1) It has been found that the steep rise in adsorption with increasing acidity is more than an electrostatic effect. In acid there is a significant dissolution of trivalent aluminum from kaolinite, and this forms a precipitation with sulfonate at low concentration. The precipitate is resolubilized at higher surfactant concentration. These effects are believed to be responsible for the shape of the isotherms in the acid region shown in figure 8.

(2) Figure 9 also shows the probable effect of aluminum. In the acid range, no significant desorption occurs when surfactant concentration is reduced, even by two orders of magnitude. When pH exceeds 6, rapid desurption occurs.

(3) In figure 10 , the trend toward negative adsorption at $\mathrm{pH} 11.5$ is ascribed to micellar exclusion. 15

(4) pH has little effect on critical micelle concentration (CMC) of alkyl-aryl sulfonates ${ }^{15,27}$ (figs. 10 and 11). This suggests that alkalinity as such would not change their partitioning into the oil phase. A change in $\mathrm{CMC}$ with $\mathrm{pH}$ may occur with ethoxylated anionic surfactants.

(5) A potentially significant factor is a change in the solution chemistry of surfactants with changing $\mathrm{pH}$. Model calculations on potassium oleate ${ }^{13}$ have indicated that the acid dimeric anion $\left(\mathrm{C}_{17} \mathrm{H}_{35} \mathrm{COO}\right)_{2} \mathrm{H}^{-}$is several orders of magnitude more strongly adsorbed than the monomer. 
These effects are negligible with low-pka sulfonic acids, but may be important with the natural surfactants generated by alkali in contact with acidic crude oil. Hingston and Posner ${ }^{28-29}$ have shown that in the case of fairly simple weak acids such as $\mathrm{H}_{3} \mathrm{PO}_{4}$, when $\mathrm{pH} \simeq \mathrm{pK}_{\mathrm{a}}$, the adsorption of the acid is accompanied by neutralization of the surface $\mathrm{OH}^{-}$and can shift the pZC.

\section{Nonionic Surfactants}

The $\mathrm{pH}$-scan in figure $12^{30}$ shows that a change from acid to neutral causes a small decrease in adsorption of polyethoxylated alkyl phenols, but there is little effect in the mildly alkaline region. It is speculated ${ }^{30}$ that one mechanism of adsorption is through hydrogen bonding to the surface hydroxyl groups $\mathrm{Al}-\mathrm{OH}$ and $\mathrm{Si}-\mathrm{OH}$, which would be altered by changes in acidity.

Figure 13 shows that there is a difference in adsorption onto hydrophilic and hydrophobic surfaces. ${ }^{31}$ Similar, but less clear-cut effects were observed with anionic surfactants by Yang et al. ${ }^{25}$ It is doubtful that the effect of alkali in increasing water wettability is sufficient to play a role here. (This is fortunate as adsorption would change in the "wrong" direction.)

With nonionics, a major parameter in adsorption or other types of retention is nearness to the cloud point, as shown in figure 14. ${ }^{32}$ Thus, alkali will affect adsorption or partitioning if it alters the colloidal nature of the surfactant solution. One indication that this happens is the data of French et al. ${ }^{9}$ As shown in figure 15, alkali-extracted Wilmington (CA) crude oil, which shows no surface activity with alkali alone, displays an immediate large drop in interfacial tension when a nonionic surfactant is present with the alkali, much faster than for the surfactant without alkali. This suggest a change in the character of the surfactant in the presence of the alkali, affecting at least the kinetics of adsorption at the liquid-liquid interface.

However, results to date do not offer much encouragement for any beneficial effect of alkali in reducing retention of nonionic surfactants, except in removing divalent cations. It is probable that weakly ionic surfactants, such as ethoxylated carboxylates, will show more change in CMC, cloud point, and electrostatic adsorption with $\mathrm{pH}$ than purely nonionic surfactants. For each type, it would be worthwhile to carry out a systematic investigation.

\section{POLYMERS}

Adsorption of ionic polymers shows an electrostatic effect like that of ionic surfactants. Figure 16 shows strong adsorption of hydrolyzed polyacrylamide at low $\mathrm{pH}$ and a decrease as $\mathrm{pH}$ is increased. ${ }^{33}$ Other anionic polymers behave similarly. ${ }^{34}$ The inverse behavior of a cationic polymer is shown in figure 17.35 The expected insensitivity to $\mathrm{pH}$ for a nonionic polymer is shown in figure 16. The adsorption is equal to the highest value observed with the anionic form at low $\mathrm{pH}$. This illustrates that the primary attractive force is probably hydrogen bonding ${ }^{36}$ through silanol and aluminol groups on the surface, which is then counteracted by electrostatic repulsion effects. When electrostatic effects are suppressed by increasing salinity, as in figure 18 , the adsorption of the hydrolyzed polymer approaches that of the nonionic form. ${ }^{37}$ It should be 
mentioned that all the measurements for figure 18 were made at a $\mathrm{pH}$ well above the $\mathrm{pZC}$, which was 1.5 .

The effect of $\mathrm{pH}$ in producing an increasingly negative surface charge is only part of its effect on electrostatic repulsion. From intrinsic viscosity measurements, ${ }^{37}$ it is known that the polymer molecule itself acquires an increasingly negative charge as $\mathrm{pH}$ increases. At very high $\mathrm{pH}$, alkalinity promotes increased hydrolysis. ${ }^{38}$ Adsorption of the more hydrolyzed polymers is lower and more reversible $2,39-40$ and can be suppressed by alkalinity. In contrast with the stereotypical behavior of nonionic polymers in figure 16, figures 19 and 20 show variations of adsorption in the very high and very low ranges of $\mathrm{pH}^{23,41}$

As for surfactants, the adsorption of polymers can be reduced by deactivation of divalent cations by alkali. 42 Insofar as alkali increases water wettability, it could be expected to increase adsorption. ${ }^{2}$ However, it is speculated that this will be counteracted by reduced mechanical entrapment. ${ }^{43}$ Another significant factor is hydrodynamically induced retention. ${ }^{44-45}$ No data have been reported showing the influence of $\mathrm{pH}$ on these effects. It is possible that they will be more pronounced as molecules expand at higher $\mathrm{pH}$ and lower salinity. If so, retention could increase even though adsorption deceases. It is evident that our ability to use alkalis to control polymer retention is limited by a paucity of definitive data. The important conclusion is that the impact of alkalinity on polymer retention should be studied primarily under dynamic conditions. 46

\section{NOTES ON MINERAL CHEMISTRY}

A preponderance of studies of the influence of alkali on adsorption has been with kaolinite. It would be rash to generalize to other reservoir minerals. For example, Krumrine ${ }^{47}$ found that a silicate alkali did not reduce the adsorption of a petroleum sulfonate on montmorillonite. Figure 21 shows that in the case of calcite and gypsum, the dissolution of calcium overwhelms the simple adsorption of a sulfonate induced by electrostatic and micellar effects. It would be valuable to study the response of this solubility effect to alkali, especially in regard to kinetics. There have been few studies of adsorption on dolomite, either with or without alkali, although this is a common reservoir material and might be expected to behave differently from either calcite or magnesite.

Figure 22 shows that kaolinite has a buffering effect on brine 48.49 between $\mathrm{pH} 4$ and 10 . This must be taken into account in experimental adjustment of $\mathrm{pH}$. It is also important to monitor $\mathrm{pH}$ changes during adsorption, which have been observed with kaolinite, $26,50-52$ alumina, 51 and Berea sandstone. ${ }^{14}$

\section{ALTERNATIVE ANIONS}

Even though sodium hydroxide provides the highest alkalinity at the lowest cost, other alkaline agents are generally more economical because of greater effectiveness. Table 2 shows that this is particularly true with respect to suppressing retention. As in the case of interfacial activity, 53 the effect of various anions is not definitively correlated with $\mathrm{pH}$. However, $\mathrm{pH}$ is one of the 
factors to be considered, along with buffer capacity, ionic strength, deactivation of divalent cations, and, of course, consumption by reservoir solids.

Among the practical alternatives to sodium hydroxide, the carbonate/bicarbonate system has the simplest chemistry. Although there is evidence of slow and complex equilibriua, ${ }^{53}$ the system is probably the most easily controlled and stabilized. Carbonate has been shown ${ }^{8,47,54}$ to reduce adsorption of anionic surfactants to a modest extent and has been used for reservoir conditioning. ${ }^{42,55}$ Its effect is largely to increase $\mathrm{pH}$, but it also functions by precipitating divalent cations. In flow experiments with petroleum sulfonate and Berea, Krumrine ${ }^{11}$ found that surfactant was retained initially, but was released during a saline postflush following sodium carbonate. This peculiar effect is shown in figure 23 .

Silicates have been recognized ${ }^{4}, 11$ as being very effective in reducing surfactant retention. Much of the work with silicates has been at a $\mathrm{pH}$ higher than that attainable with the carbonate system. Data in table 5 suggest that silicate should strongly reduce the adverse effects of magnesium and iron, but that calcium is more completely eliminated by carbonate and phosphate (especially since phosphate forms soluble complexes with calcium). However, because of the multiplicity of ionic species and crystalline forms of silicates and phosphates, the effectiveness seen in the last column of table 2 differs from that expected from tabulated solubilities. As for polymers, the performance of alkalis needs to be evaluated from flow experiments.

Silicates are characterized by the ratio $\mathrm{n}=\mathrm{SiO}_{2} / \mathrm{Na}_{2} \mathrm{O}$. A larger value of $\mathrm{n}$ results in anions that are larger (more $\mathrm{SiO}_{2}$ units per unit charge) and more complex (fig. 24), so that they have more points of attachment. Multidentate ions tend to adsorb irreversibly ${ }^{29}$-- a fact well recognized with polymers. These properties promote sequestering of divalent cations by adsorption on colloidal particles, and also cause steric blocking of adsorption sites. ${ }^{52}$ The reduced retention of a petroleum sulfonate with an increase in $\mathrm{n}$ is shown in table 2. The same effect is shown for sodium dodecylbenzene sulfonate on kaolinite in figure 25 . Increasing $n$ improves the effectiveness in two ways: lower adsorption and a more rapid decrease with i...reasing $\mathrm{pH}$. It is obvious that silicate is much superior to carbonate for this system. For an ethoxylated sulfate on Berea, conin aring the results of Nelson et al..$^{57}$ with those of Peru and Lorenz, ${ }^{54}$ it appears that silicate is superior to sodium bicarbonate by an order of magnitude in reducing adsorption.

Figure 26 shows that the performance of silicate in the system of figure 25 can be greatly improved by addition of a small amount of partly hydrolyzed polyacrylamide. The author 52 suggest that a large amount would have a negative effect because of the increase in ionic strength. Under flowing conditions, one would expect that the enhancing effect of polyacrylamide would be lost rapidly by retention of the polymer.

Silicate solutions can come to equilibrium with purely siliceous material but are subject to consumption by aluminosilicates. ${ }^{58-59}$ To achieve $\mathrm{pH}$ levels that are benign with respect to mineral 
reactions, it is necessary to have low concentrations along with a high value of $\mathrm{n}$, as shown in figure 27.60 However, silicate "solutions" with $n>2$ are really colloidal dispersions (fig. 28) that are unstable on the time scale of field operations. ${ }^{60}$

Complex phosphates, most notably the tripolyphosphate $11\left(\mathrm{P}_{3} \mathrm{O}_{10^{-5}}\right)$ and hexametaphosphate ${ }^{25}\left(\mathrm{P}_{6} \mathrm{O}_{18^{-6}}\right)$ are almost as effective as silicate in reducing retention of surfactants in the laboratory. They are also capable of effecting some desorption of polyacrylamides. ${ }^{61}$ But the complex phosphates are also unstable on the time scale of field operations, as they hydrolyze to the orthophosphate $\left(\mathrm{PO}_{4}{ }^{-3}\right)$. For example, at pri 9 and $130^{\circ} \mathrm{F}$ the half-life of the tripolyphosphate is 50 days. ${ }^{62}$ This reaction is faster at low pH, but (unlike the silicates) the phosphate remains soluble. As shown in table 6, the orthophosphate is considerably less effective than silicate in reducing adsorption at a given $\mathrm{pH}$. It is also interesting that an increase of $\mathrm{pH}$ enhances the benefit of silicate, but has no effect on the orthophosphate.

\section{CONCLUSIONS}

1. Alkali reduces the retention of surfactants and polymers in chemical flooding.

2. The effect is often not large in the practical $\mathrm{pH}$ range.

3. The benefit of alkali in reducing adsorption of ionic surfactants and polymers is greater at low salinity.

4. Observed variations with surfactant and solid indicate that the benefit of alkali can be enhanced by tailoring the surfactant to the reservoir.

5. Surfactant characteristics that need to be considered are the sensitivity to divalent cations and salt and the colloidal behavior (CMC and cloud point).

6. The effect of alkali on nonionic surfactants and polymers is minor.

7. There are no data on the effect of alkali on the mechanical entrapment of polymers, which is an important mechanism of retention.

8. The effects of specific minerals include the $\mathrm{pH}$ of zero charge, the solubilities of gypsum and carbonates, the effect of $\mathrm{pH}$ on hydroxyl groups available for hydrogen bonding, and the buffering effect of the solid. There is a paucity of data on the important minerals montmorillonite and dolomite.

9. Complex silicates and phosphates are more effective in reducing adsorption than hydroxide or carbonates, but are unstable on the time scale of field operations. 


\section{RECOMMENDED RESEARCH}

1. Investigations are needed on the effect of alkalis on $\mathrm{CMC}$, cloud point, and partitioning of surfactants. Emphasis should be placed on ethoxylated surfactants (nonionic, sulfonates, and carboxymethylated) with various HLB values.

2. The abundant research on adsorption on silica and kaolinite should be extended to other aluminosilicates and well-defined calcareous materials, especially dolomite.

3. Dynamic experiments should be performed to evaluate the effect of alkalis on mechanical entrapment of polymers.

4. Methods should be devised to stabilize silicates at high values of $n$. For example:

- low concentrations of silicates for the specific interaction with $\mathrm{Mg}$ and $\mathrm{Fe}$, and for blocking of adsorption sites, mixed with larger concentrations of phosphate or carbonate for buffer capacity, and

- surfactants that solubilize the colloidal complex anions.

5. Note that the reduction of retention is just one factor in design on the surfactant-alkali process. Various requirements will have to be balanced to achieve an optimum, and retention behavior may have to be explored under less-than-ideal conditions.

\section{REFERENCES}

1. Friedman, F. Surfactant and Polymer Losses During Flow through Porous Media. Pres. at Soc. Pet. Eng. International Symposium on Oilfield and Geothermal Chemistry, Denver, CO, June 1-3, 1983. SPE paper 11779.

2. Lakatos, I., J. Lakatos-Szabo, and J. Toth. Factors Influencing Polyacrylamide Adsorption in Porous Media and Their Effect on Flow Behavior. In: Surface Phenomena in Enhanced Oil Recovery, D.O. Shah, Ed. Plenum Press, New York, 1981, pp. 821-842.

3. Whitely, R.C. and J.C. Ware. Low Tension Waterflood Pilot at the Salem Unit, Marion County, Illinois - Part 1. Field Implementation and Results. J. Pet. Tech., Oct. 1977, pp. 925-932. 
4. Holm, L.W. and S.D. Robertson. Improved Micellar/Polymer Flooding with High pH Chemicals. J. Pet. Tech., Jan. 1981, pp. 161-172.

5. Bae, J.H. and C.B. Petrick. Adsorption/Retention of Petroleum Sulfonates in Berea Cores. Soc. Pet. Eng. J., Oct. 1977, pp. 353-357.

6. Somasundaran, P. and H.S. Hanna. Adsorption of Sulfonates on Reservoir Rocks. Soc. Pet. Eng. J., Aug. 1979, pp. 221-232.

7. Douglas, L.J. Designing Miceller Displacement Systems to Minimize Adsorption. U.S. Patent 3,971,439, July 1976.

8. Hurd, B.G. Adsorption and Transport of Chemical Species in Laboratory Surfactant Waterflooding Experiments. Pres. at Soc. Pet. Eng. Symposium on Improved Oil Recovery, Tulsa, OK, Mar. 22-24, 1976. SPE Paper 5818.

9. French, T.R., D.A. Peru, and S.D. Thornton. Low pH Alkaline Chemical Formulations. U.S. Dept of Energy Report No. NIPER-375, Jan. 1989. NTIS order No. DE89000724.

10. French, T.R. Design and Optimization of Phosphate-Containing Alkaline Flooding Formulations. U.S. Dept. of Energy Report No. NIPER-446, Feb. 1990. NTIS order No. DE90000217.

11. Krumrine, P.H., J.S. Falcone, Jr., and T.C. Campbell. Surfactant Flooding 1: The Effect of Alkaline Additives on IFT, Surfactant Adsorption, and Recovery Efficiency. Soc. Pet. Eng. J., August 1982, pp. 503-513.

12. Krumrine, P.H. and J.S. Falcone, Jr. Beyond Alkaline Flooding: Design of Complete Chemical Systems. Pres. at Soc. Pet., Eng. Internationai Symposium on Oilfield Chemistry, San Antonio, TX, Feb. 4-6, 1987. SPE Paper 16280.

13. Somasundaran, P. Adsorption from Flooding Solutions in Porous Media: Annual Report, 1978, (NSF Grant No. ENG-76-08756), July 1978.

14. Hanna, H.S. and P. Somasundaran. Physico-Chemical Aspects of Adsorption at Solid/Liquid Interfaces. II Mahogany Sulfonate/Berea Sandstone, Kaolinite. In: Improved Oil Recovery by Surfactant and Polymer Flooding, Ed. D.O. Shah and R.S. Schechter. Academic Press, Inc., New York 1977, pp. 253-274. 
15. Baviere, M., D. Defives, J. Labrid, and L. Minssieux. Voies de recherche en matiere de recuperation assistee due petrole par tensio-actifs. Rev. Inst. Francais du Petrole, v. 42, May-June 1987, pp. 327-345.

16. Somasundaran, P. and C.C. Gryte. Adsorption from Flooding Solutions in Porous Media: Finai Report U.S. Dept. of Energy Report No. DOE/BC/10082-27, June 1985.

17. Somasundaran, P. Adsorption from Flooding Solutions in Porous Media, Annual Repurt. U.S. Dept . of Energy Report No. DOE/BC/10082-20, Feb. 1984.

18. Wade, W.H. and R.S. Schechter. Tertiary Oil Recovery Processes - Annual Report, Oct. 1978-Sept. 1979. U.S. Dept. of Energy Report No. DOE/BC/20001-6, Aug. 1980.

19. Schechter, R.S., and W.H. Wade. Tertiary Oil Recovery Processes Research at the University of Texas, Annual Report. U.S. Dept. of Energy Contract DE-AC1980BC10345. Oct. 1983.

20. Welzen, J.T.A.M., H.N. Stein, J.M. Stevels, and C.A.M. Siskens. The Influence of Surface-Active Agents on Kaolinite. J. Colloid \& Interface Sci., v. 81, June 1981, pp. 455-467.

21. Somasundaran, F. and D.W. Fuerstenau. Mechanism of Alkylsulfonate Adsorption of the Alumina-Water Interface. J. Phys. Chem, v. 70, 1966, p. 90.

22. Somasundaran, P. Adsorption from Flooding Solutions on Porcus Media: Annual Report, 1977. NSF Grant No. Eng-76-08756. Aug. 1977.

23. Somasundaran, P. Adsorption from Flooding Solutions in Porous Media, Annual Report. U.S. Dept. of Energy Report No. DOE/BC/10n\&2-2, Feb. 1980.

24. Siracusa, P.A., and P. Somasundaran. Adsorption-Desorption and Hysteresis of Sulfonates on Kaolinite: pH Effects. J. Colloid \& Interface Sci., v. 114, Nov. 1986, pp. 184-193.

25. Yang, C.-Z, W.-L. Jao, and Y.-H. Huang. The Mechanism of Adsorption and a New Method to Reduce Surfactant Loss in Chemical Flooding. J. Petr. Sci. and Eng., v. 3, 1989, pp. 97-109. 
26. Somasundaran, P. Adsorption from Flooding Solutions in Porous Media: Annual Report 1980. DOE Contract No. DE-AC19-79BC 10082, June, 1980.

27. Scamehorn, J.F., R.S. Schechter, and W.H. Wade. Adsorption of Surfactants on Mineral Oxide Surfaces from Aqueous Solutions. 1. Isomerically Pure Anionic Surfactants. J. Colloid \& Interface Sci., v. 85, Feb. 1982, pp. 463-477.

28. Hingston, F.J., A.M. Posner, and J.P. Quirk. Anion Adsorption by Goethite and Gibbsite. I. Role of the Proton in Determining Adsorption Envelopes. J. Soil Sci., v. 23, 1972, pp. 177-92.

29. Hingston, F.J., A.M. Posner, and J.P. Quirk. Anion Adsorption on Goethite and Gibbsite. II. Desorption on Anions from Hydrous Oxide Surfaces. J. Soil Sci., v. 25, 1974, pp. 16-26.

30. Schechter, R.S., and W.N. Wade. Research on Tertiary Oil Recovery, Annual Report. U.S. Energy Research Administration Contract EY-76-02-0031. *000, April 1977.

31. Furlong, D.N., and J.R. Aston. Adsorption of Polyoxyethylated Nonyl Phenols at Silica/Agueous Solution Interfaces. J. Colloids and Surfaces, v. 4, 1982. pp. 121-129.

32. Verkruyse, L.A., and S.J. Salter. Potential Use of Nonionic Surfactants in Micellar Flooding. Pres. at International Soc. Pet. Eng. Symposium of Oilfield and Geothermal Chemistry, Phoenix, AZ, Apr. 9-11, 1985. SPE Paper 13574.

33. Chauveteau, G., J. LeCourtier, and L.T. Lee. Polymer Flooding: A New Method for Selecting the Optimal Polymer Chemical Structure for Given Reservoir Conditions. Proc., 4th BASF AG ET AL Enhanced Oil Recovery Symposium, Hamburg, Germany, Oct. 27-29, 1987, pp. 79-90.

34. Hollander, A.F., P. Somasundaran, and C.C. Gryte. Adsorption Characteristics of Polyacrylamide and Sulfonate-Containing Polyacrylamide Copolymers on Sodium Kaolinite. J. Appl. Polym. Sci., v. 26, 1981, pp. 2123-2138.

35. Somasundaran, P., and C.C. Gryte. Adsorption from Flooding Solutions in Porous Media, Second Annual Report. J.W.S. Dept. of Energy Report No. DOE/BC/10082-8, Apr. 1982. 
36. LeCourtier, J. and G. Chauveteau. Adsorption des polyacrylamides et du xanthane sur des surfaces minerales. Proc.,AGIP 3d European Meeting on Improved Oil Recovery, Rome, Apr. 16-18, 1985, pp. 187-198.

37. LeCourtier, J., L.T. Lee, and G. Chauveteau. Adsorption of Polyacrylamides on Siliceous Minerals. J. Colloids and Surfaces, v. 47, July 1990, pp. 219-231.

38. Ryles, R.G. Chemical Stability Limits Water-Soluble Polymers Used in Oil Recovery Processes. Pres. at Soc. Pet. Eng. International Symposium on Oilfield and Geothermal Chemistry, Phoenix, AZ, Apr. 9-11, 1985. SPE Paper 13585.

39. Somasundaran, P. and C.C. Gryte. Adsorption from Flooding Solutions in Porous Media. Third Annual Report. U.S. Dept. of Energy Report No. DOE/BC/10082-12, Jan. 1983.

40. Martin, F.D., and N.S. Sherwood. The Effect of Hydrolysis of Polyacrylamide on Solution Viscosity, Polymer Retention, and Flow Resistance Properties. Pres. at Soc. Pet. Eng. Rocky Mountain Meeting, Denver, CO, Apr. 7-9, 1975. SPE Paper 5339.

41. Nabzar, L. and E. Pefferkorn. An Experimental Study of Kaolinite Crystal-Edge Polyacrylamide Interactions in Dilute Suspension. J. Colloid \& Interface Sci., v. 108, Nov. 1985, pp. 243-248.

42. Wier, D.R., and D.D. Bruning. Post-Primary Oil Recovery Employing Thickened Aqueous Alkaline Flood. Canadian Patent 1,142,336, Mar. 1983.

43. Cohen, Y., and F.R. Christ. Polymer Retention and Adsorption in the Flow of Polymer Solutions Through Porous Media. Soc. Pet. Eng. Reservoir Engineering, March 1986, pp. 113-118.

44. Chauveteau, G. and N. Kohler. Polymer Flooding: The Essential Elements for Laboratory Evaluation. Pres. at Soc. Pet. Eng. Symposium on Improved Oil Recovery, Tulsa, OK, Apr. 22-24, 1974. SPE Paper 4745.

45. Willhite, G.P., and J.G. Dominquez. Mechanisms of Polymer Retention in Porous Media. In: Improved Oil Recovery by Surfactant and Polymer Flooding, Ed. D.O. Shah and R.S. Schechter, Academic Press, Inc., New York, 1977, pp. 511-554. 
46. Zaitoun, A., and N. Kohler. The Role of Adsorption in Polymer Propagation Through Reservoir Rocks. Pres. at Soc. Pet. Eng. International Symposium on Oilfield and Geothermal Chemistry, San Antonio, TX, Feb. 4-6, 1987. SPE Paper 16274.

47. Krumrine, P.H., I.B. Ailin-Pyzik, and J.S. Falcone, Jr. The Effect of Alkaline Chemicals on the Adsorption of Anionic Surfactants by Oil Reservoir Substrates. Pres. at Symposium on Chemistry of Enhanced Oil Recovery, American Chemical Society, Atlanta, GA, Mar. 29 - Apr. 3, 1981.

48. Somasundaran, P., and C.C. Gryte. Adsorption from Flooding Solutions in Porous Media, Annual Report. U.S. Dept. of Energy Report No. DOE/BC/10082-24, Jan. 1985.

49. Defives, D. and B. Bazin. Effer du pH sur la propagation d'un bouchon de tensioactif anionique. Proc., AGIP 3d European Conference on Improved Oil Recovery, Rome, April 16-19, 1985, v. 2, pp. 163-170.

50. Somasundaran, P. Adsorption from Flooding Solutions in Porous Media: Annual Report, 1983, DOE Contract No. DE-AC19-79BC 10082. June 1983.

51. Somasundaran, P. Adsorption from Flooding Solutions in Porous Media: Annual Report, 1984, DOE Contract No. DE-AC19-79BC 10082. June 1984.

52. Yang, C.Z. and D.K. Han. Control of the Adsorption of Sodium Alkylbenzene Sulfonate in Solution on Clay by Polyelectrolyte. Proc., AGIP 3d European Meeting on Improved Oil Recovery, Rome, Apr. 16-18, 1985. Proceedings, v. 2, pp. 177-186.

53. Lorenz, P.B. Combination Alkaline-Surfactant Flooding: A State of the Art Review. U.S. Dept. of Energy Report No. NIPER-349, October 1988.

54. Peru, D.A., and P.B. Lorenz. Surfactant-Enhanced Low pH Alkaline Flooding. Soc. Pet. Eng. Reservoir Engineering, Aug. 1990, pp. 327-332.

55. Rivenq, R., M. Sardin, and D. Schwiech. Sodium Carbonate Preflush: Theoretical Analysis and Application to Chateaurenard Field Test. Pres. at SPE Annual Technical Conference and Exhibition, Las Vegas, NM, Sept. 22-25, 1985. SPE Paper 14294. 
56. Krumrine, P.H. Mechanisms of Retention in Silicate Enhanced Dilute Surfactant Low Tension Floods. Pres. at Soc. Pet. Eng. International Symposium on Oilfield and Geothermal Chemistry, Dallas, TX, Jan. 25-27, 1982. SPE Paper 10604.

57. Nelson, R.C., J.B. Lawson, D.R. Thigpen, and G.L. Stegemeier. CosurfactantEnhanced Alkaline Flooding. Pres. at Fourth SPE/DOE Symposium on Enhanced Oil Recovery, Tulsa, OK, Apr. 15-18, 1984. SPE/DOE Paper 12672.

58. Thornton, S.D. Adverse Effects of Mineral-Alkali Reactions in Alkaline Flooding. U.S. Dept. of Energy Report No. NIPER-273, Jan. 1988. NTIS order No. DE88001209.

59. Thornton, S.D. and P.B. Lorenz. Mineral-Alkali Reactions under Dynamic Conditions. U.S. Dept. of Energy Report No. NIPER-340, Aug. 1988. NTIS order No. DE88001253.

60. Krumrine, P.H. and J.S. Falcone, Jr. Rock Dissolution and Consumption Phenomena in an Alkaline Recovery System. Pres. at SPE/DOE 4th Symposium on Enhanced Oil Recovery, Tulsa, OK, Apr. 16-18, 1984. SPE/DOE Paper 12670.

61. Dodson, P.J. and P. Somasundaran, Desorption of Polyacrylamide and Hydrolyzed Polyacrylamide from Kaolinite Surface. J. Colloid \& Interface Sci., v. 97, Feb. 1984, pp. 481-487.

62. Van Wazer - J.R. Phosphorus and It's Compounds, Vol. I Chemistry. Interscience Publishers, Inc., 1958. 
TABLE 1. - Adsorption ( $\mu$ eq/g) of Petrostep B-100 (0.1 wt\%) on Berea sand ${ }^{1}$

\begin{tabular}{lll}
\hline $\mathrm{pH}$ & $\frac{\mathrm{wt} \%}{0.0}$ & $\frac{\mathrm{NaCl}}{0.3}$ \\
\hline
\end{tabular}

Batch experiments, crushed Berea, $25^{\circ} \mathrm{C}$

\begin{tabular}{rll}
\hline${ }^{2} 6.3$ & 0.66 & 1.06 \\
${ }^{3} 10.0$ & 0.59 & 0.83 \\
\hline
\end{tabular}

Flowing experiments, high-permeability Berea, $52^{\circ} \mathrm{C}$

\begin{tabular}{rr}
26.3 & 0.38 \\
310.0 & 0.19 \\
\hline
\end{tabular}

${ }^{1}$ From reference 10.

2Natural $\mathrm{pH}$.

${ }^{3} 0.13 \mathrm{eq} / \mathrm{dm}^{3} \mathrm{Na}_{2} \mathrm{HPO}_{4}, 0.065 \mathrm{eq} / \mathrm{dm}^{3} \mathrm{Na}_{2} \mathrm{CO}_{3}, 0.0325 \mathrm{eq} / \mathrm{dm}^{3} \mathrm{NaHCO}_{3}$ 
TABLE 2. - Effect of various alkalis on surfactant retention and effluent hardness in flowing experiments through Berea core ${ }^{1}$

\begin{tabular}{|c|c|c|c|c|c|}
\hline Alkali & wt \% & $\begin{array}{c}\text { Approximate } \\
\text { pH }\end{array}$ & $\begin{array}{c}\text { Salinity/ } \\
\text { alkalinity } \\
\mathrm{Na}_{2} \mathrm{O} \\
\end{array}$ & $\begin{array}{c}\text { Surfactant } \\
\text { retaincd, } \\
\mathrm{mg} / \mathrm{g} \\
\end{array}$ & $\begin{array}{r}\text { Effluent } \\
\text { hardness }{ }^{3} \\
\text { ppm } \mathrm{CaC}_{3}\end{array}$ \\
\hline None & - & 7.3 & - & 0.68 & $100-300$ \\
\hline $\mathrm{NaOH}$ & 1.0 & 13.0 & 0.63 & 0.65 & $10-20$ \\
\hline $\mathrm{Na}_{5} \mathrm{P}_{3} \mathrm{O}_{10}$ & 0.38 & 8.8 & - & 0.18 & - \\
\hline $\mathrm{Na}_{3} \mathrm{PO}_{4}$ & 0.38 & 11.0 & 0.22 & 0.28 & 10 \\
\hline $\mathrm{Na}_{2} \mathrm{CO}_{3}$ & - & 10.6 & 0.22 & 0.26 & $20-40$ \\
\hline \multicolumn{6}{|c|}{ SILYATE: 4} \\
\hline $\mathrm{n}=0.5$ & 1.0 & 13.0 & 0.44 & 0.25 & 10 \\
\hline $\mathrm{n}=1.6$ & 0.43 & - & ${ }^{5} 0.28$ & 0.20 & 10 \\
\hline $\mathrm{n}=3.2$ & 0.38 & 10.4 & 0.21 & 0.15 & 10 \\
\hline
\end{tabular}

${ }^{1}$ Based on data from references 11 and 12. Core was 2 in. $x 1 \mathrm{ft}$. Injected slug was ca. 3 PV of $0.25 \%$ Petrostep 450 and $1.0 \% \mathrm{NaCl}$.

${ }^{2}$ (Conductivity in reciprocal ohn-meters)/(Na20 content in wt\%).

${ }^{3}$ Connate hardness $4,800 \mathrm{ppm}$.

${ }^{4} \mathrm{n}=\mathrm{SiO}_{2} / \mathrm{Na}_{2} \mathrm{O}(\mathrm{mol} / \mathrm{mol})$.

SInterpolated. 
TABLE 3. - Adsorption ( $\mu \mathrm{eq} / \mathrm{g})$ at CMC of cationic and anionic surfactants on kaolinite ${ }^{1}$

\begin{tabular}{cccc}
\hline Surfactant & $\begin{array}{c}\text { CMC, } \\
\text { m mol/d } \mathrm{dm}^{3}\end{array}$ & 3 & 10 \\
\hline $\mathrm{CTAB}^{2}$ & 1 & 36 & 50 \\
$\mathrm{SDS}^{3}$ & 10 & 33 & 7 \\
\hline
\end{tabular}

${ }^{1}$ Data from reference 20.

${ }^{2}$ Cetyl trimethylammonium bromide.

${ }^{3}$ Sodium decyl sulfate. 
TABLE 4. - Adsorption of sodium dodecylbenzene sulfonate ${ }^{1}$ on sodium kaolinite at $30^{\circ} \mathrm{C}^{2}$

\begin{tabular}{|c|c|c|c|c|}
\hline \multirow[b]{2}{*}{ Salinity, mol/dm ${ }^{3} \mathrm{NaCl}$} & \multicolumn{2}{|c|}{$\mathrm{pH} 6.5$} & \multicolumn{2}{|c|}{$\mathrm{pH} 9.4$} \\
\hline & 0.01 & 0.10 & 0.01 & 0.10 \\
\hline Adsorption, $\mu \mathrm{mol} / \mathrm{g}$ & 14.00 & 18.00 & 6.40 & 12.00 \\
\hline
\end{tabular}

${ }^{1}$ Isometric mixture, recrystallized.

2 Data from reference 6. 
TABLE 5. - Alkali salt solubilities in water at $\sim 25^{\circ} \mathrm{C}^{1}$

Formula weight/dm $3 \times 10^{4}$

\begin{tabular}{|c|c|c|c|c|}
\hline & \multicolumn{4}{|c|}{ Formula wcight/dm ${ }^{3} \times 10^{4}$} \\
\hline & $\mathrm{Ca}$ & $\mathrm{Mg}$ & Dolomite & $\mathrm{Fc}(\mathrm{II})$ \\
\hline Carbonate & 1.4 & 13.0 & 17.0 & 5.8 \\
\hline Metasilicate & 8.2 & $10^{-20}$ & $\rightarrow$ & -1 \\
\hline Orthophosphate & 0.6 & - & $\cdot$ & 36.0 \\
\hline
\end{tabular}

${ }^{1}$ Data from Handbook of Chemistry and Physics, 47th Edition (1986-67);

except magnesium silicatc from Thornton, NIPER-273 (1988). 
TABLE 6. - Effect of metasilicatc and orthophosphate on adsorption ${ }^{1}$ at two $\mathrm{pH}$ levels ${ }^{2}$

\begin{tabular}{|c|c|c|}
\hline & $\mathrm{pH} 6.5$ & $\mathrm{pH} 9.4$ \\
\hline \multicolumn{3}{|c|}{ Adsorption at maximum in isotherm } \\
\hline $\mathrm{NaCl}$ & 1.9 & 1.1 \\
\hline $\mathrm{Na}_{2} \mathrm{HPO}_{4}$ & 1.1 & 1.1 \\
\hline $\mathrm{Na}_{2} \mathrm{SiO}_{3}$ & 0.4 & 0.0 \\
\hline \multicolumn{3}{|c|}{ Adsorption at concentration $50 \mathrm{~m} \mathrm{~mol} / \mathrm{dm}^{3}$} \\
\hline $\mathrm{NaCl}$ & 0.9 & 0.7 \\
\hline $\mathrm{Na}_{2} \mathrm{HPO}_{4}$ & 0.4 & 0.4 \\
\hline $\mathrm{Na}_{2} \mathrm{SiO}_{3}$ & 0.2 & -0.2 \\
\hline
\end{tabular}

${ }^{1}$ Adsorption in $\mu \mathrm{mol} / \mathrm{m}^{2}$, recrystallized sodium dodecylbenzene sulfonate in brine at ionic strength $0.1 \mathrm{eq} / \mathrm{dm}^{3}$, on sodium kaolinite.

${ }^{2}$ Data from reference 6. 


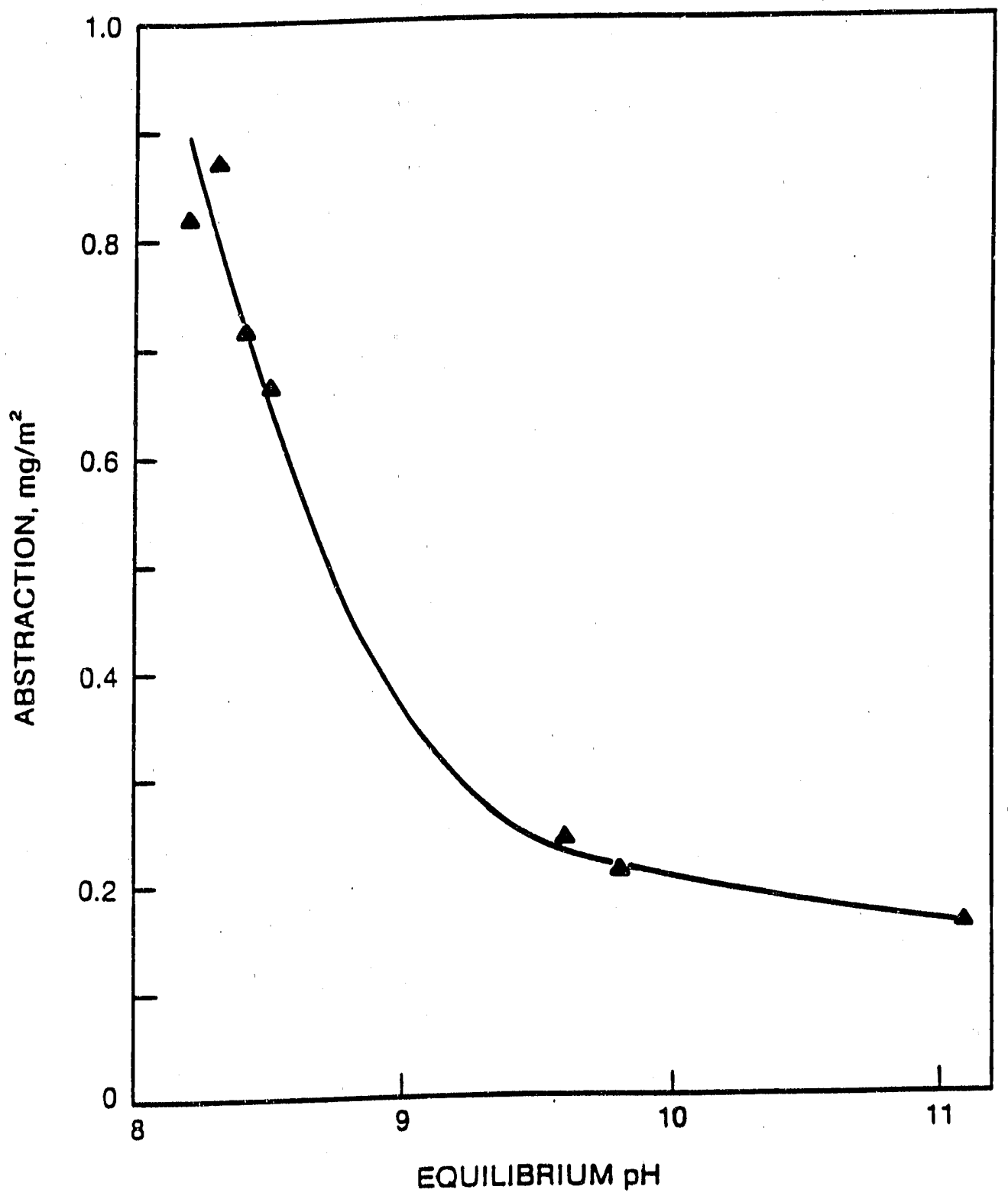

FIGURE 1. - Effect of $\mathrm{pH}$ on the abstraction of Mahogany AA sulfonate (initial concentration $12.6 \mathrm{~g} / \mathrm{dm}^{3}$ active) on Bedford limestone. Solid/Liquid ratio $(\mathrm{S} / \mathrm{L}):=1 / 1 ; 30^{\circ} \mathrm{C} ; 0.01 \mathrm{M} \mathrm{NaCl}$. (After Somasundaran and Hanna. ${ }^{6}$ ) 


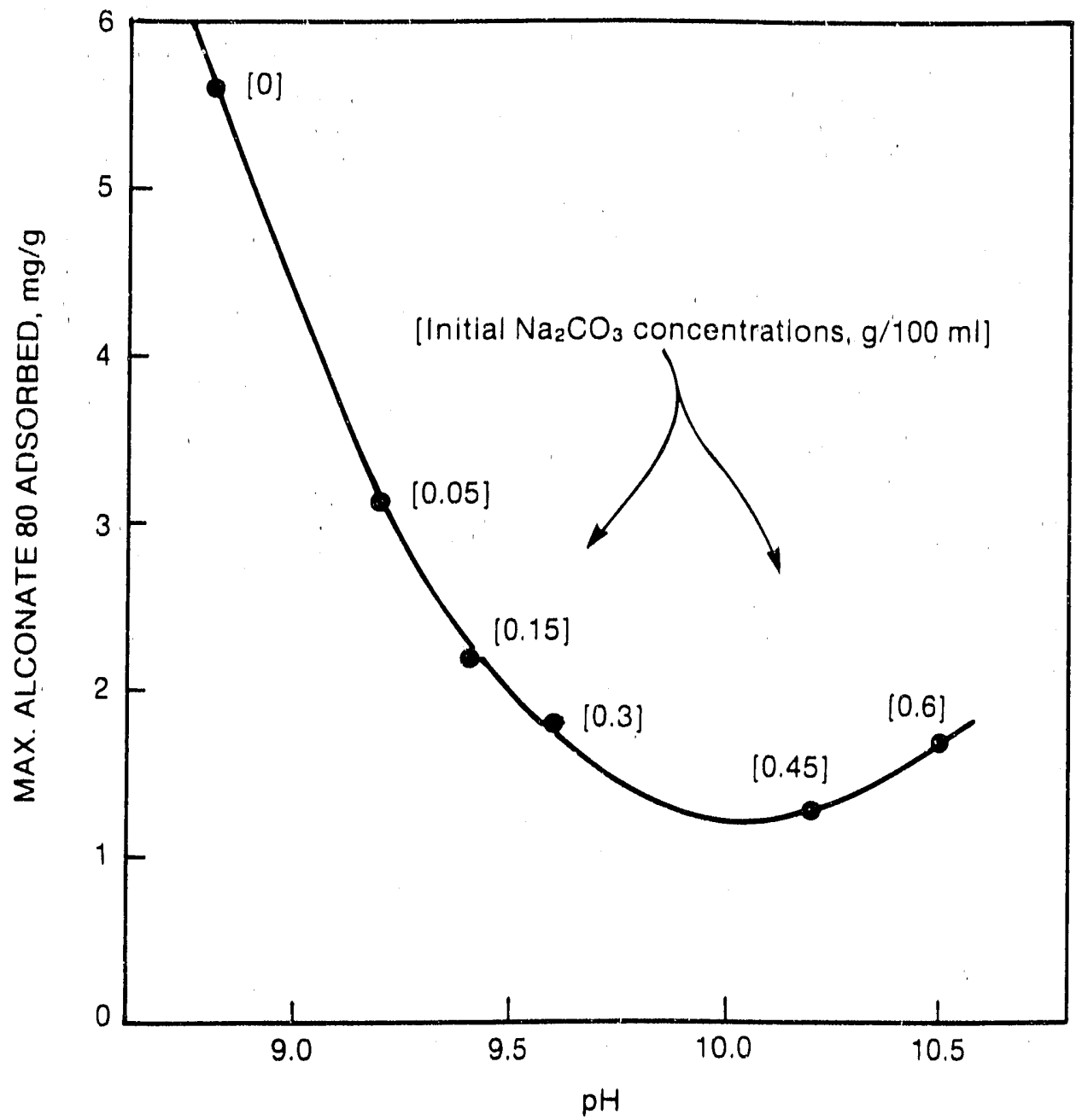

FIGURE 2. - Effect of the pH of a carbonate brine on adsorption of a petroleum sulfonate on crushed Loma Novia (TX) sandstone, $25^{\circ} \mathrm{C}$. (After Hurd. ${ }^{8}$ ) 


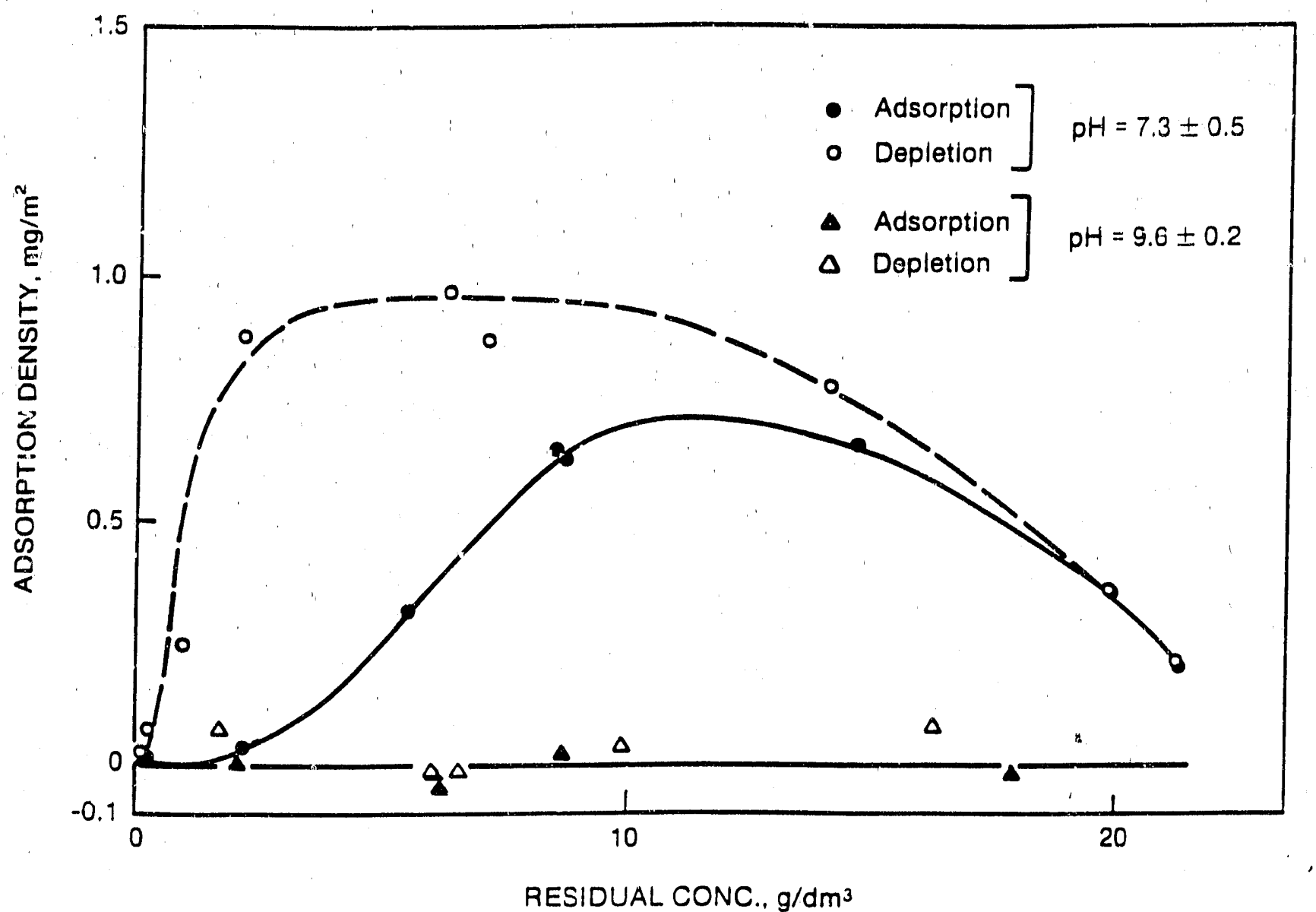

FIGURE 3. - Adsorption and depletion isotherms of a petroleum sulfonate (MW 390) on ground Berea sandstone $\left(1.5 \mathrm{~m}^{2} / \mathrm{g}\right) . \mathrm{S} / \mathrm{L}=2 / 3 ; 30^{\circ} \mathrm{C} ; 0.2 \mathrm{~m}\left(\mathrm{NH}_{4}\right)_{2} \mathrm{SO}_{4}$. (After Somasundaran. ${ }^{13}$ ) 


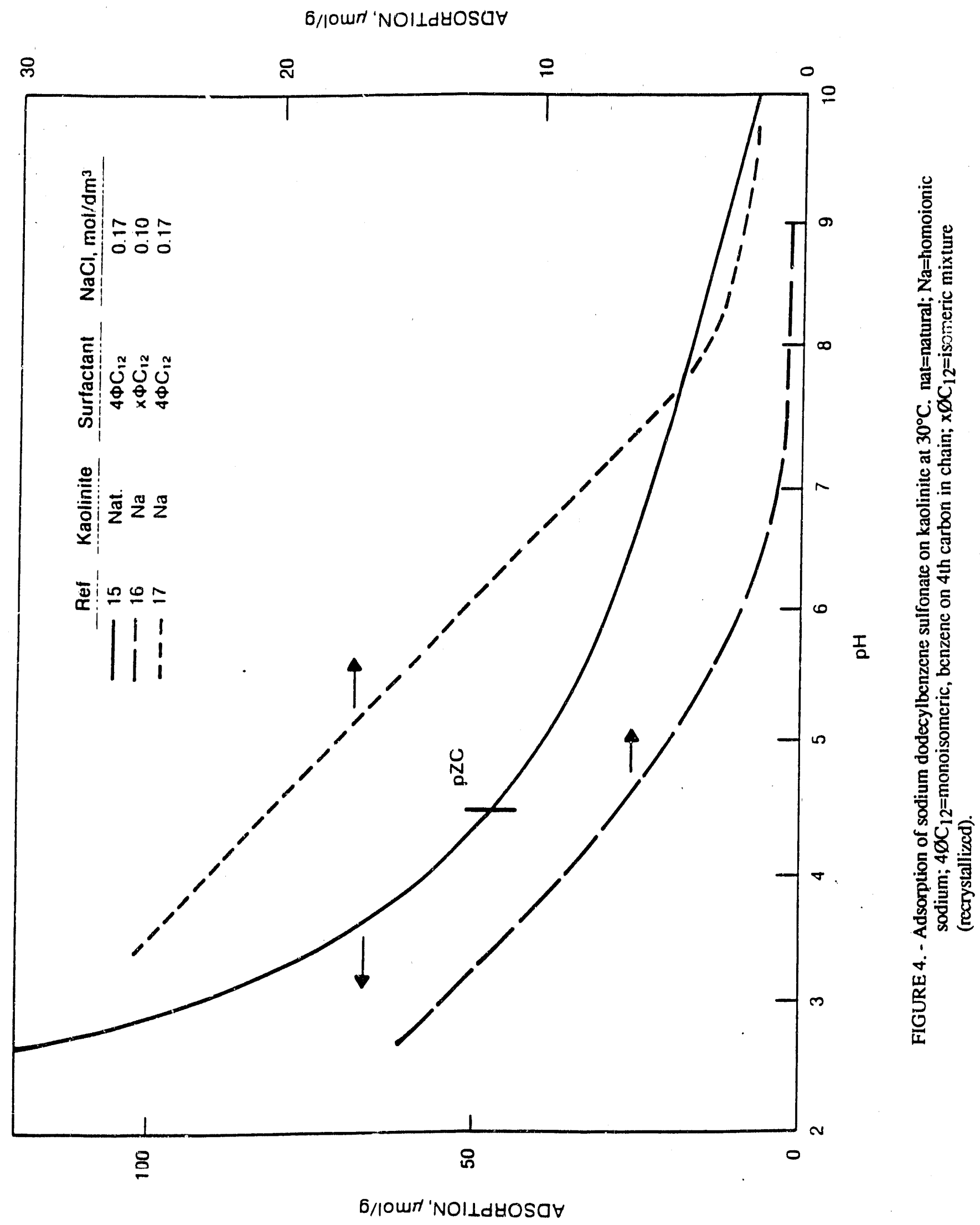




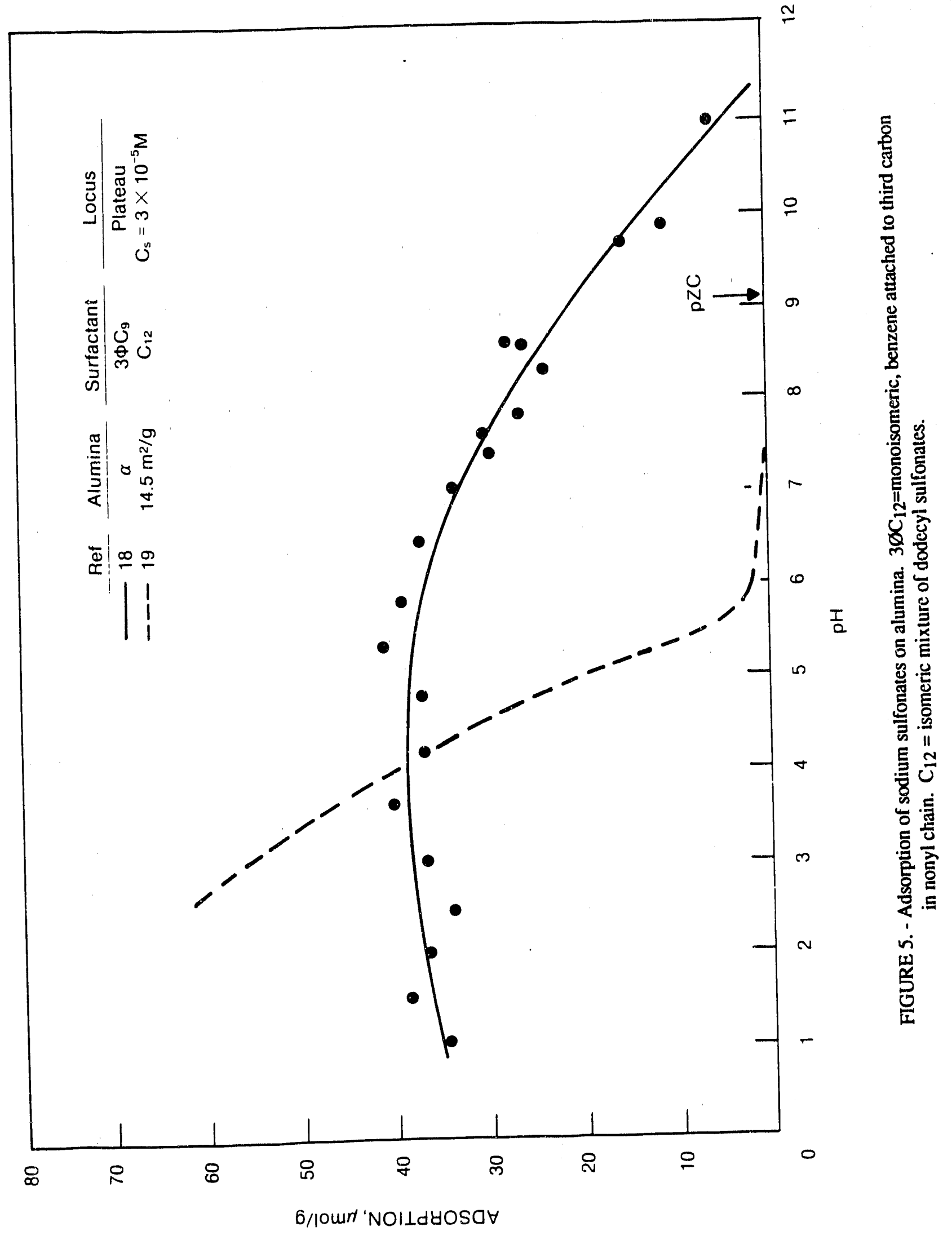




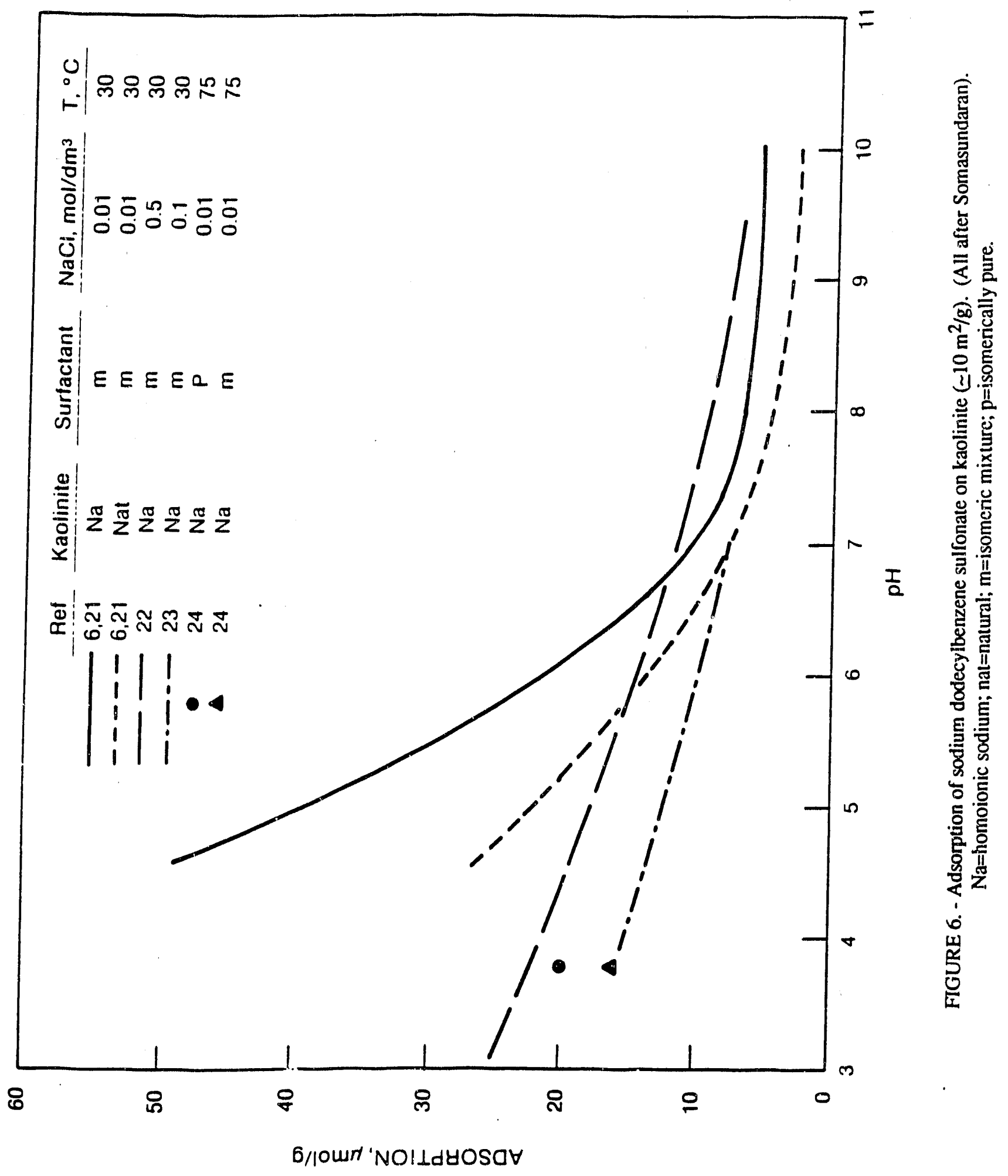




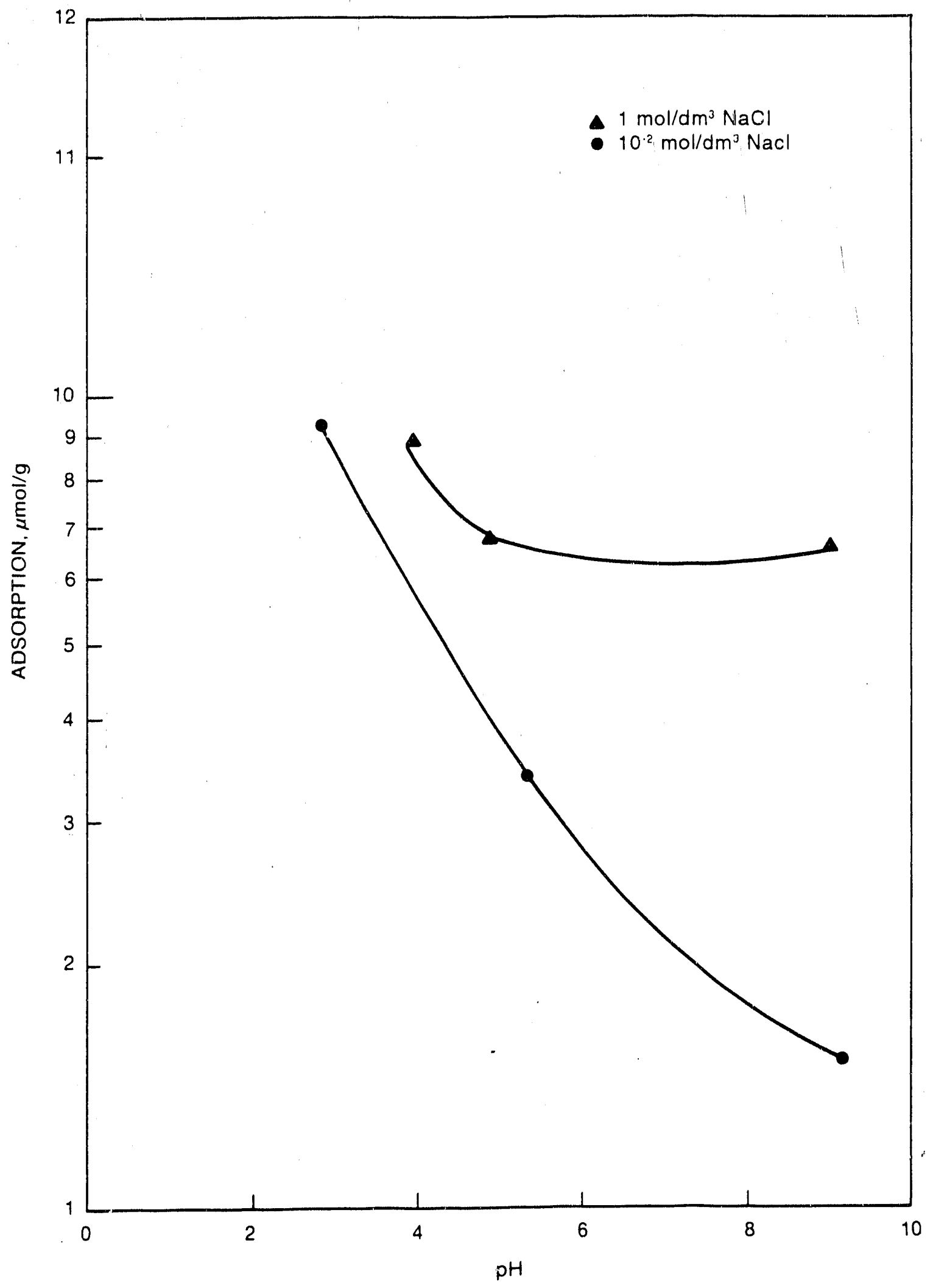

FIGURE 7. - Adsorption of sodium dodecylsulfonate $\left(2.06 \mathrm{~m} \mathrm{~mol} / \mathrm{dm}^{3}\right)$ on sodium kaolinite at $30^{\circ} \mathrm{C} . \mathrm{S} / \mathrm{L}=1 / 5$. (After Somasundaran. ${ }^{26}$ ) 


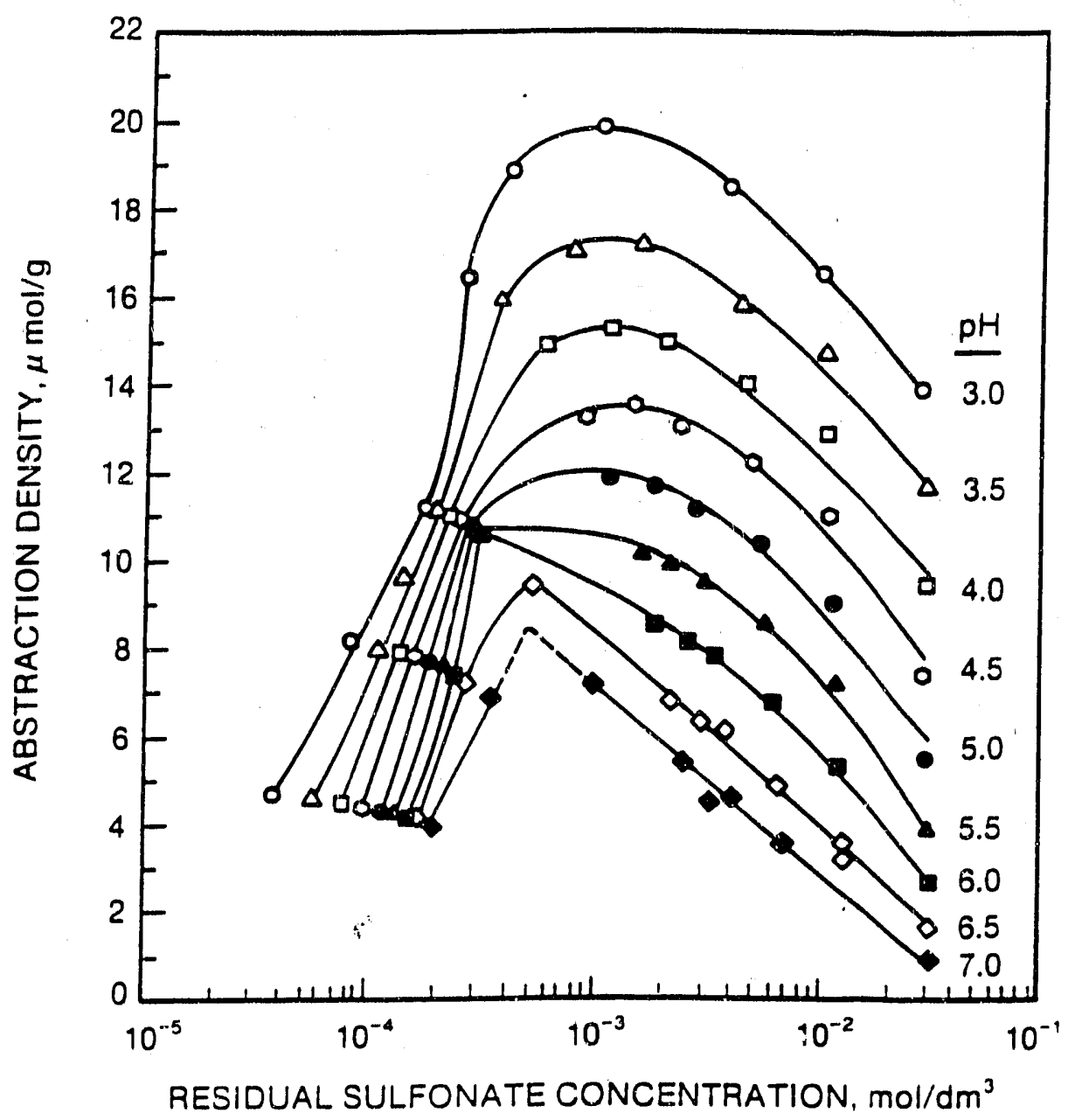

FIGURE 8. - Abstraction isotherms for sodium dodecylbenzene sulfonate (recrystallized isomeric mixture) on sodium kaolinite. $\mathrm{S} / \mathrm{L}=1 / 5 ; 30^{\circ} \mathrm{C} ; 0.1 \mathrm{M} \mathrm{NaCl}$. (After Siracusa and Somasundaran. ${ }^{24}$ ) 


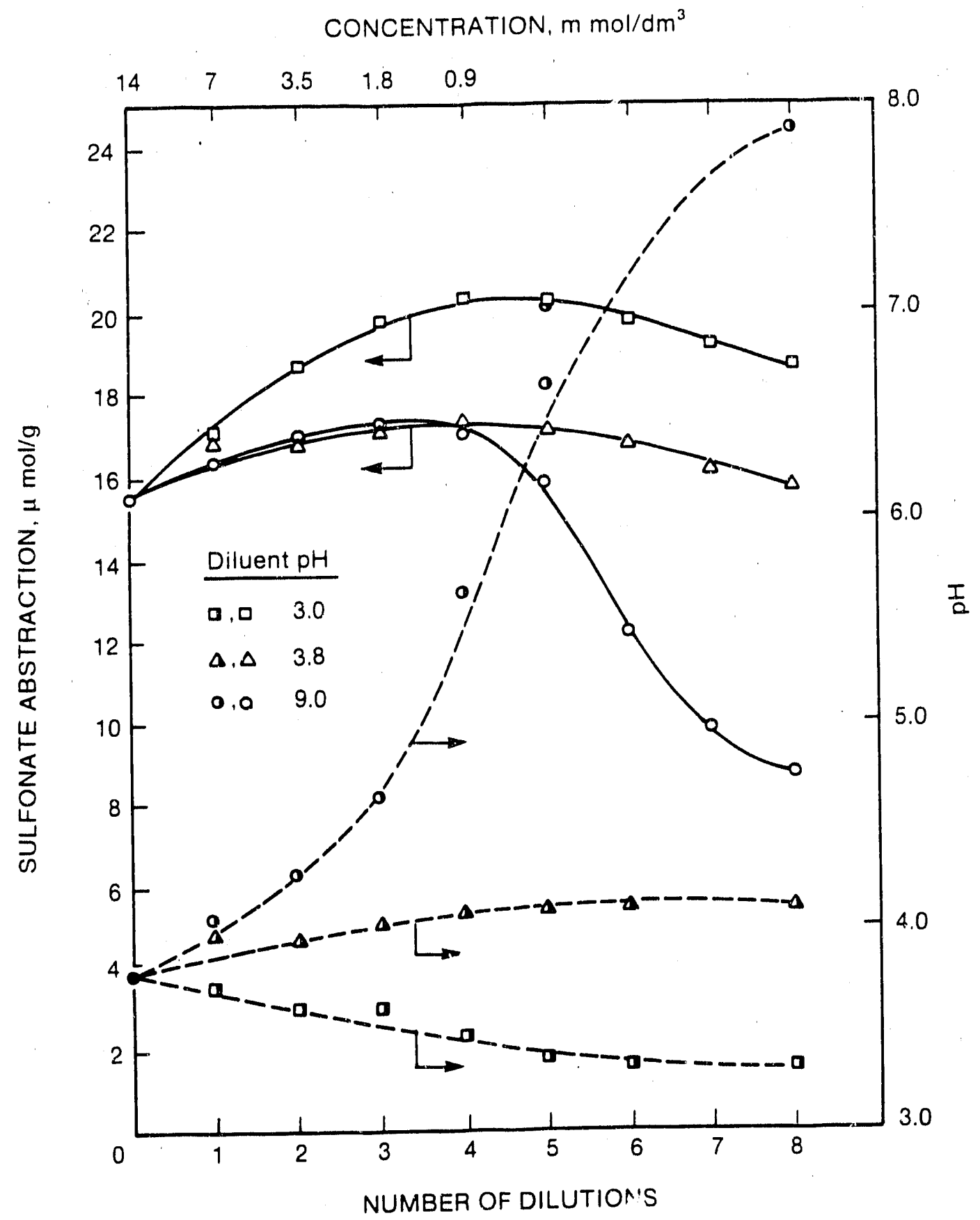

FIGURE 9. - Change in abstraction and system $\mathrm{pH}$ in a series of $\mathrm{pH}$-adjusted $50 \%$ dilutions of sodium dodecylbenzene sulfonate (recrystallized isomeric mixture) on sodium kaolinite. Original pH 3.8. S/L maintained at $1 / 5 ; 30^{\circ} \mathrm{C} ; 0.1 \mathrm{M} \mathrm{NaCl}$. (After Siracusa and Somasundaran. ${ }^{24}$ ) 


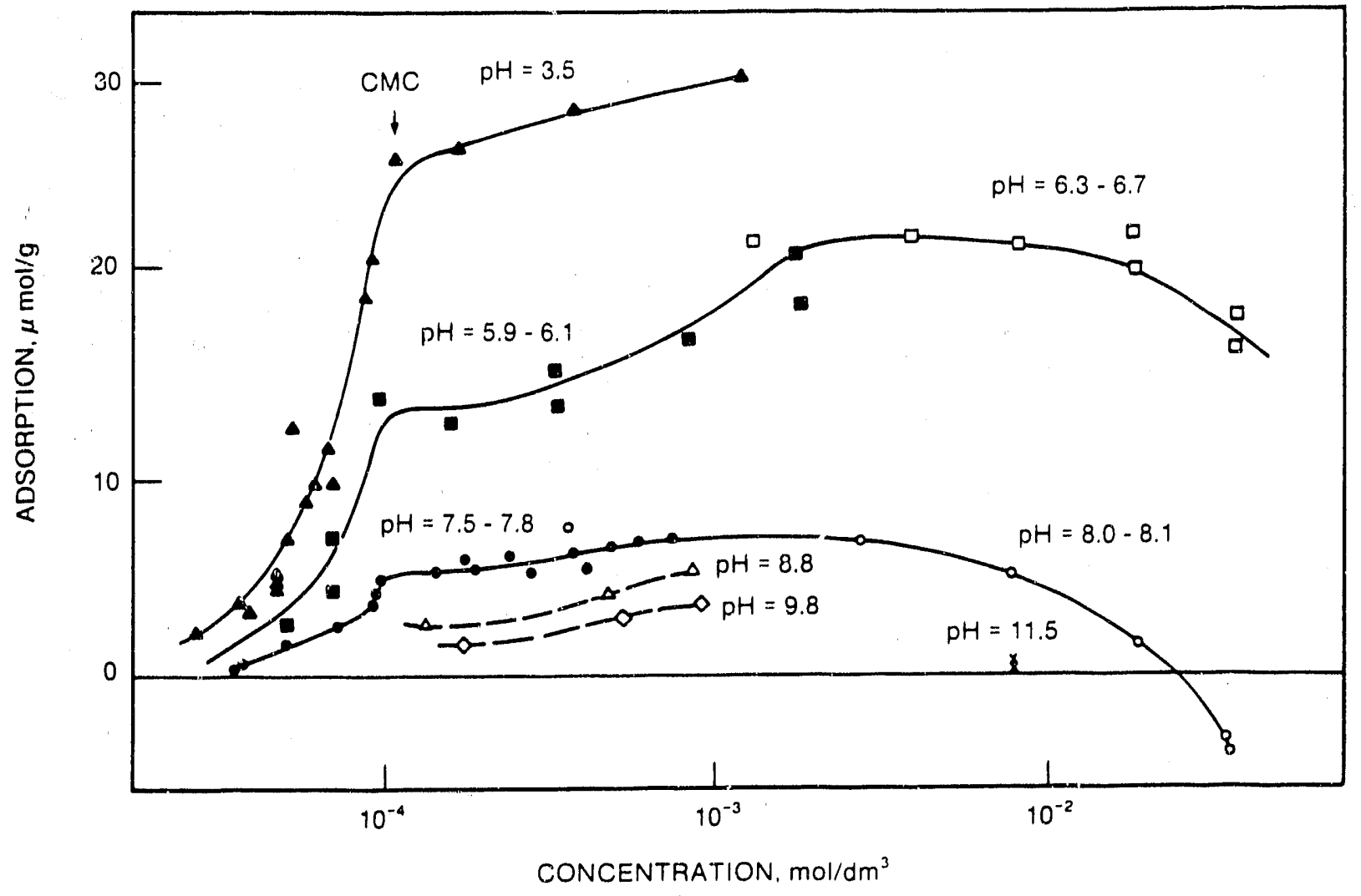

FIGURE 10. - Effect of pH on adsorption of monoisomeric sodium dodecylbenzene sulfonate (benzene on fourth carbon in chain) on homoionic sodium kaolinite. $S / L=1 ; 119 ; 30^{\circ} \mathrm{C} ; 0.17 \mathrm{M} \mathrm{NaCl}$. (After Baviere et al. ${ }^{15}$ ) 


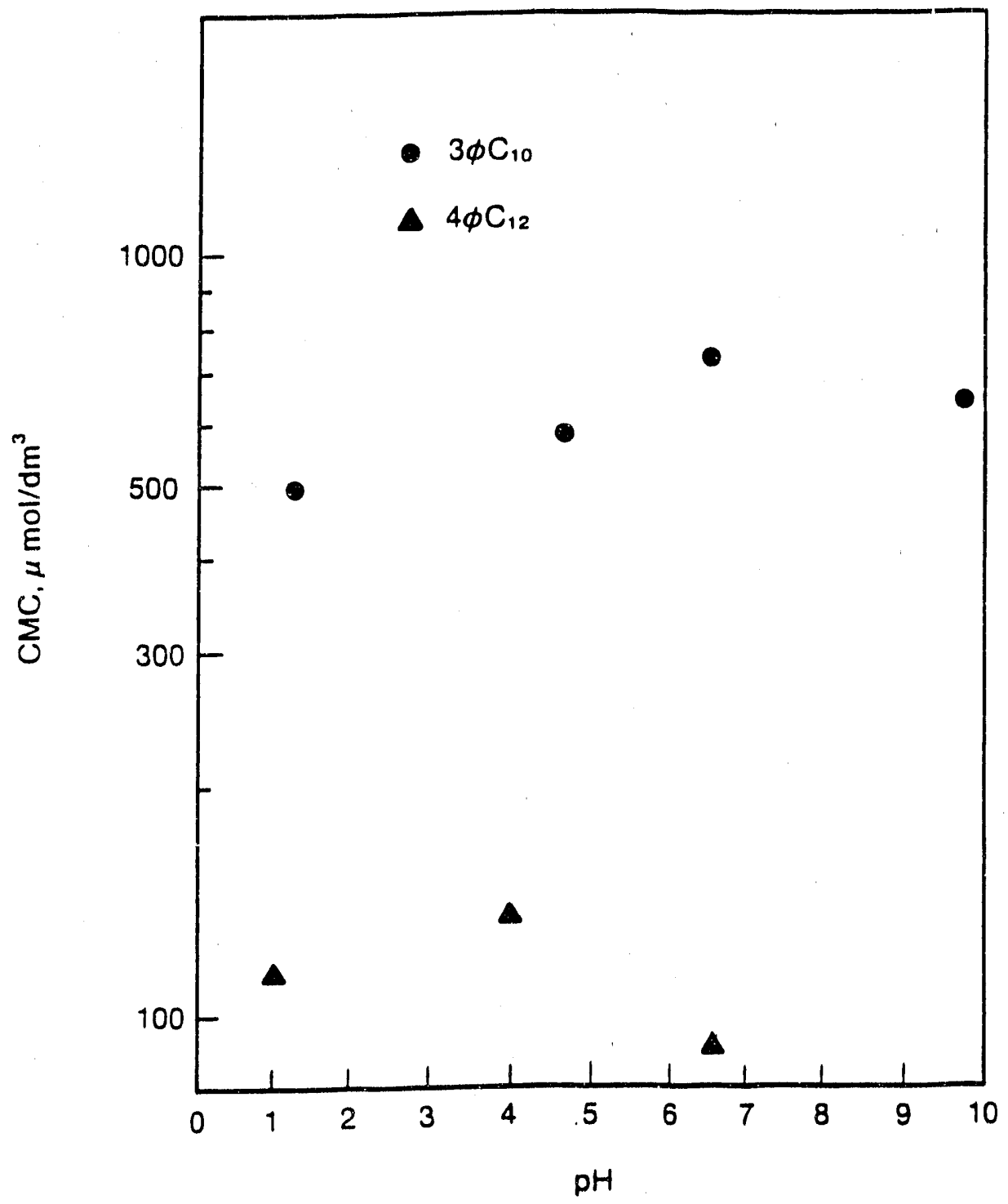

FIGURE 11. - Effect of pH on CMC of isomerically pure sodium alklylbenzene sulfonates. $3 \varnothing C_{10}=$ benzene on third carbon of decyl chain; $4 \varnothing C_{12}=$ benzene on fourth carbon of dodecyl chain. $25^{\circ} \mathrm{C} ; 0.17 \mathrm{M} \mathrm{NaCl}$. (After Scamehorn et al. ${ }^{27}$ ) 


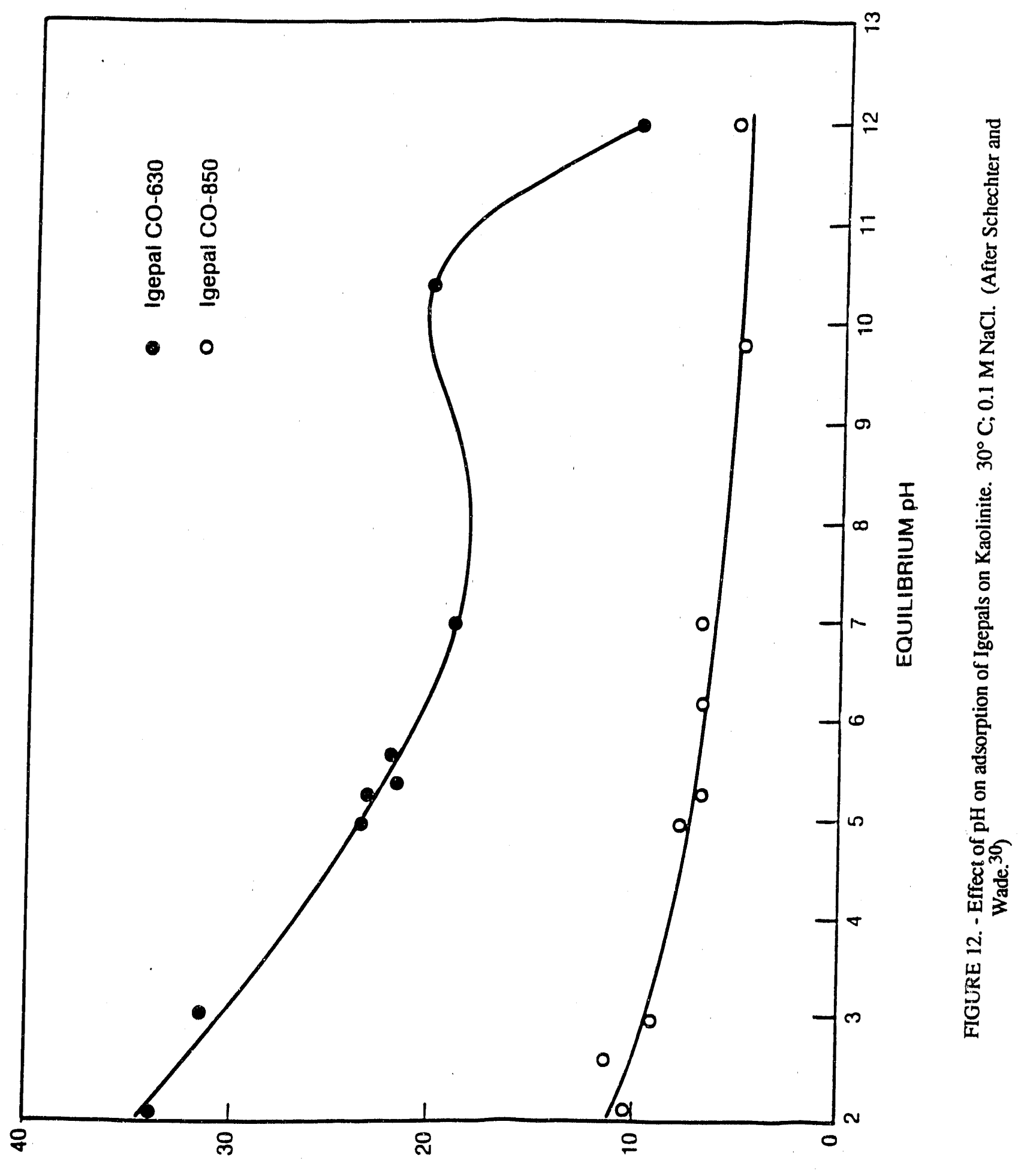

6/10س $\pi$ 'NOILdHOSA 


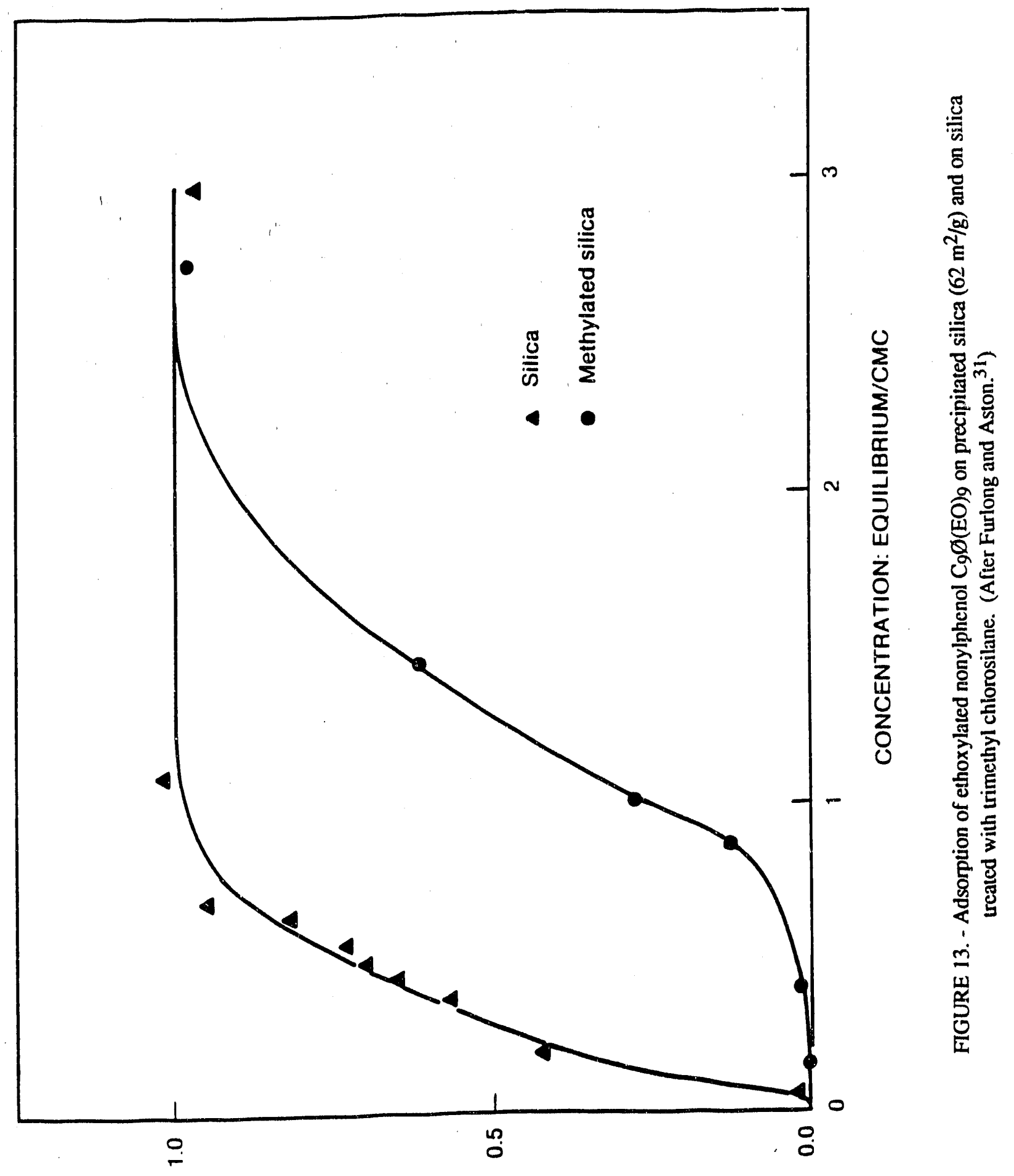

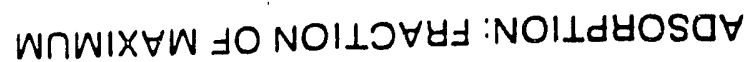




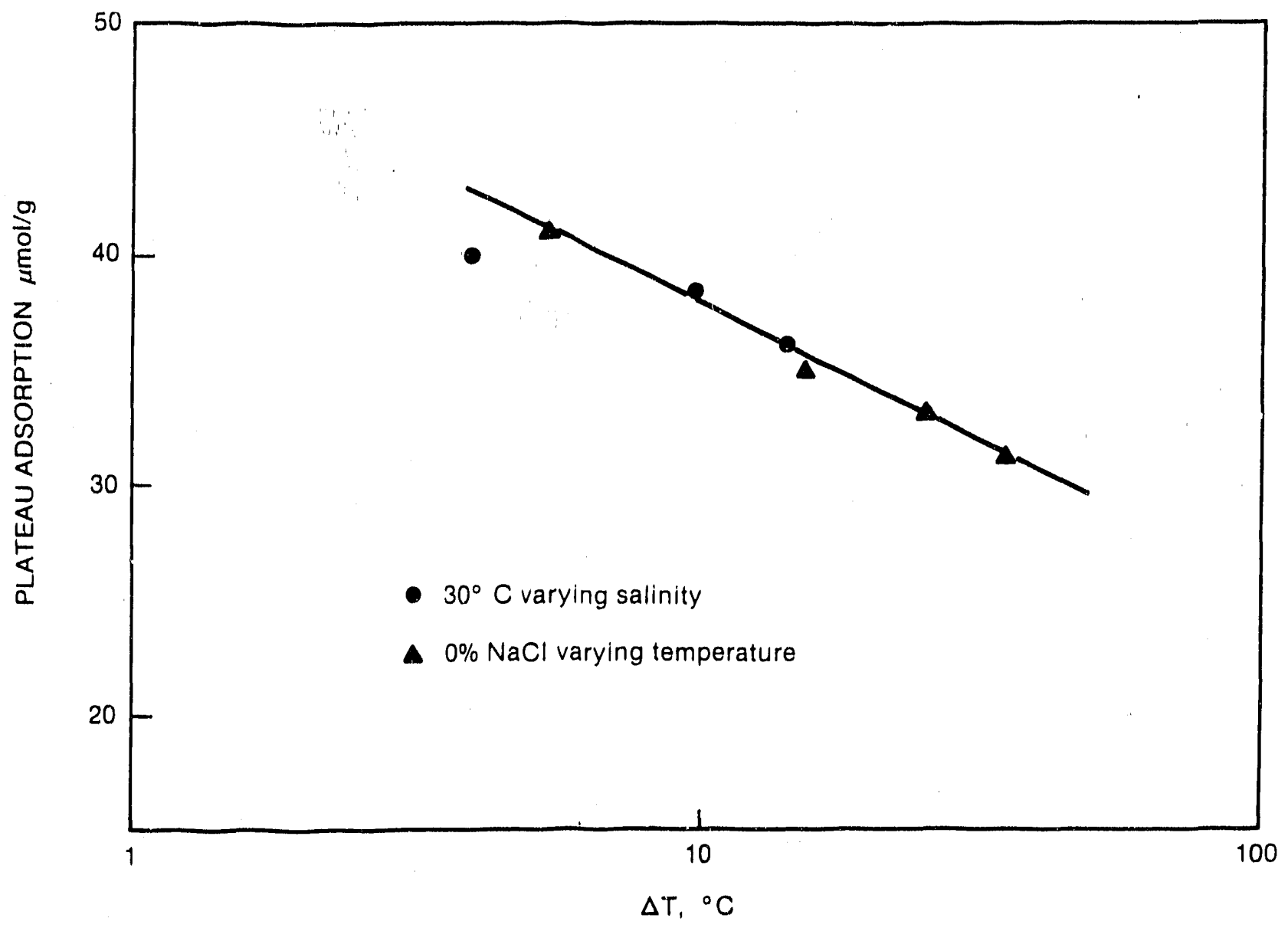

FIGURE 14. - The effect of cloud point on adsorption of Igepal CO-630 on kaolinite. $\Delta \mathrm{T}=$ cloud point adsorption temperature. (After Verkruyse and Salter. ${ }^{32}$ ) 


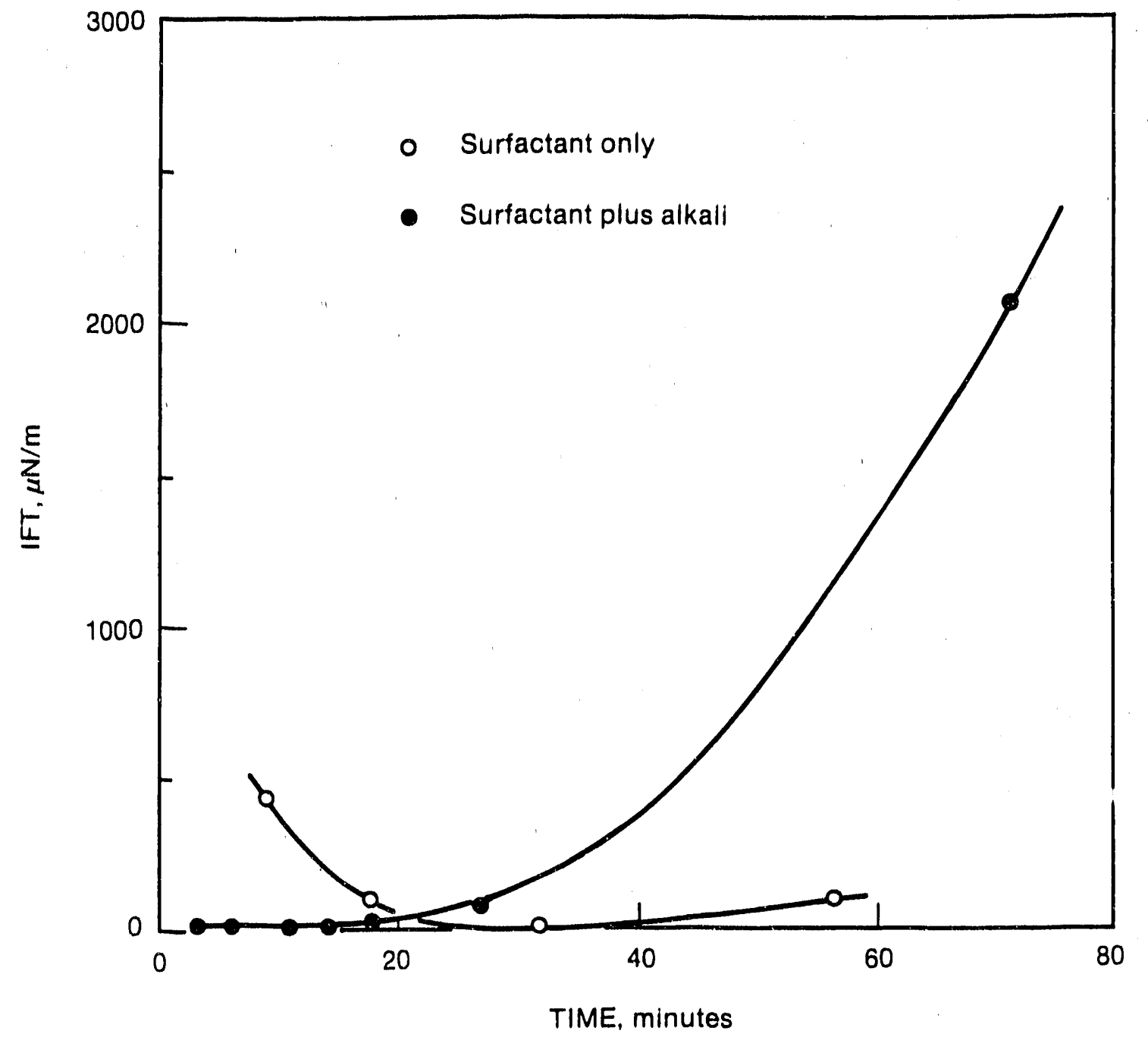

FIGURE 15. - Transient interfacial tension of deacidified Wilmington (CA) cruje oil and 0.1\% Neodol 25-9. Alkali is $0.19 \mathrm{~N}$ equimolar mixture of $\mathrm{Na}_{2} \mathrm{CO}_{3}$ and $\mathrm{NaHCO}_{3}, \mathrm{pH}$ 10.8. (After French et al. ${ }^{9}$ ) 


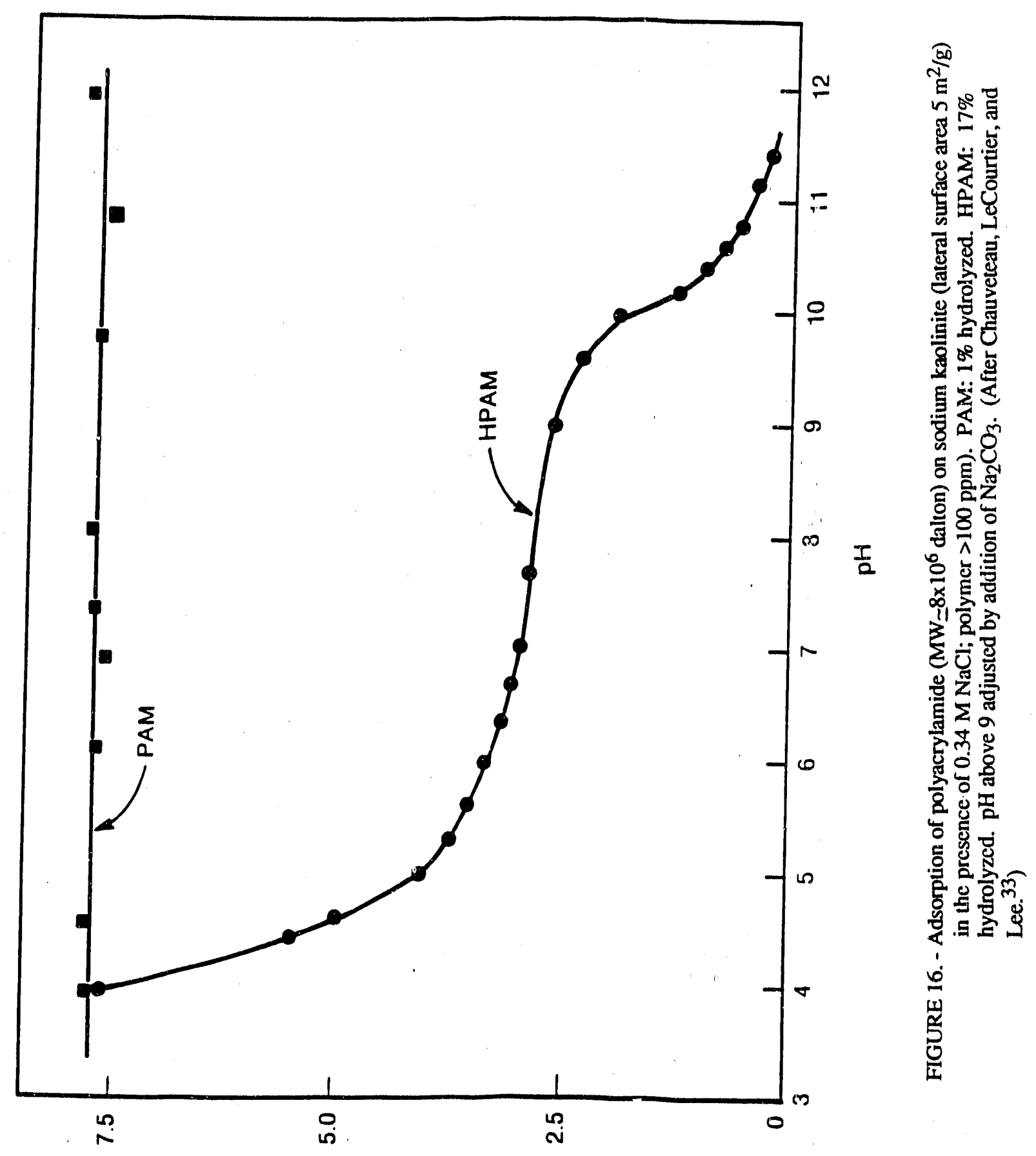

6/6u 'NOILdyOSOY 


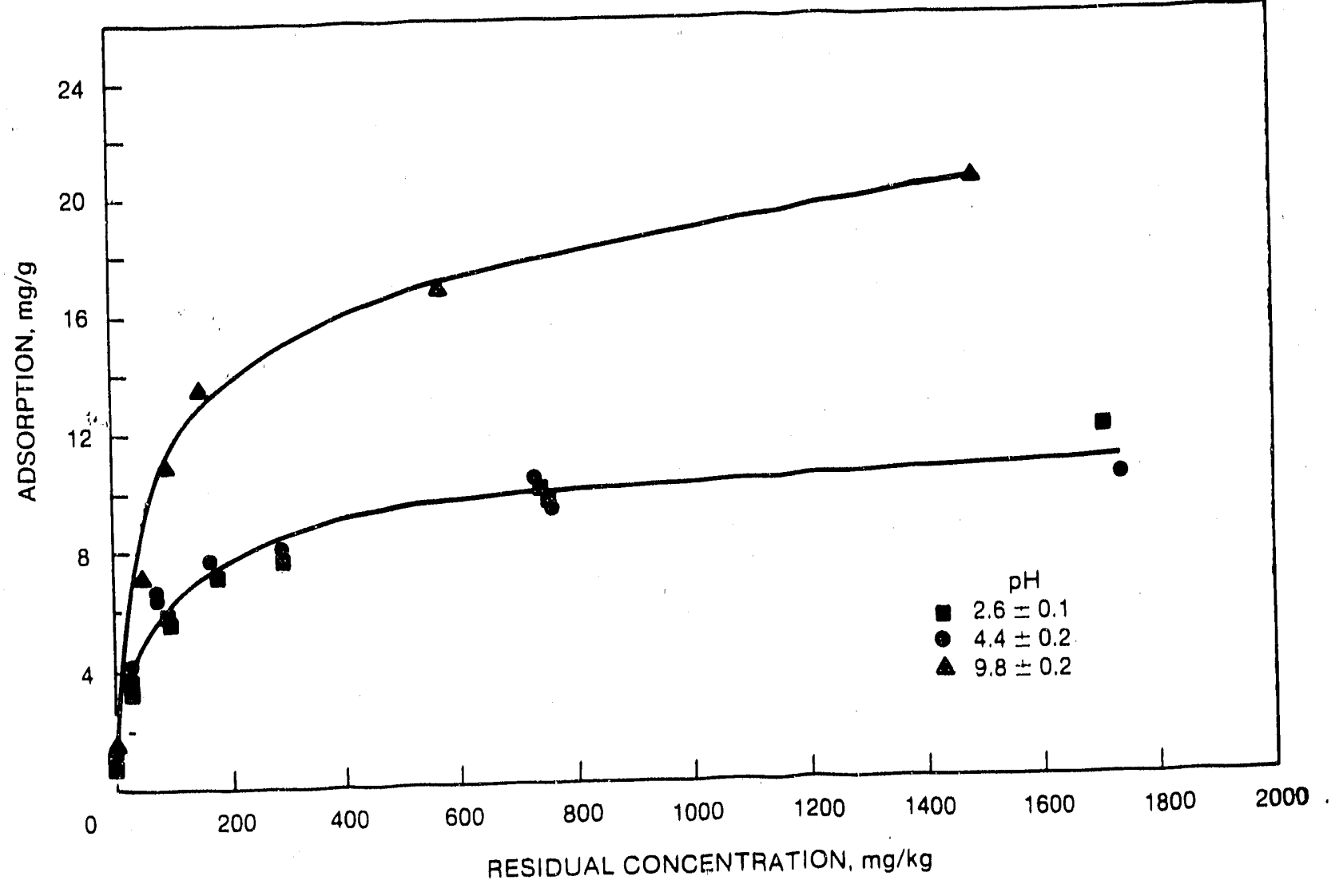

FIGURE 17. - Adsorption isotherms for aminated polyacrylamide (10 mol\% positive charge) on silica (Biosil). $\mathrm{S} / \mathrm{L}=1 / 40 ; 25^{\circ} \mathrm{C} ; 0.03 \mathrm{M} \mathrm{NaCl}$. (After Somasundaran and Gryte. ${ }^{35}$ ) 


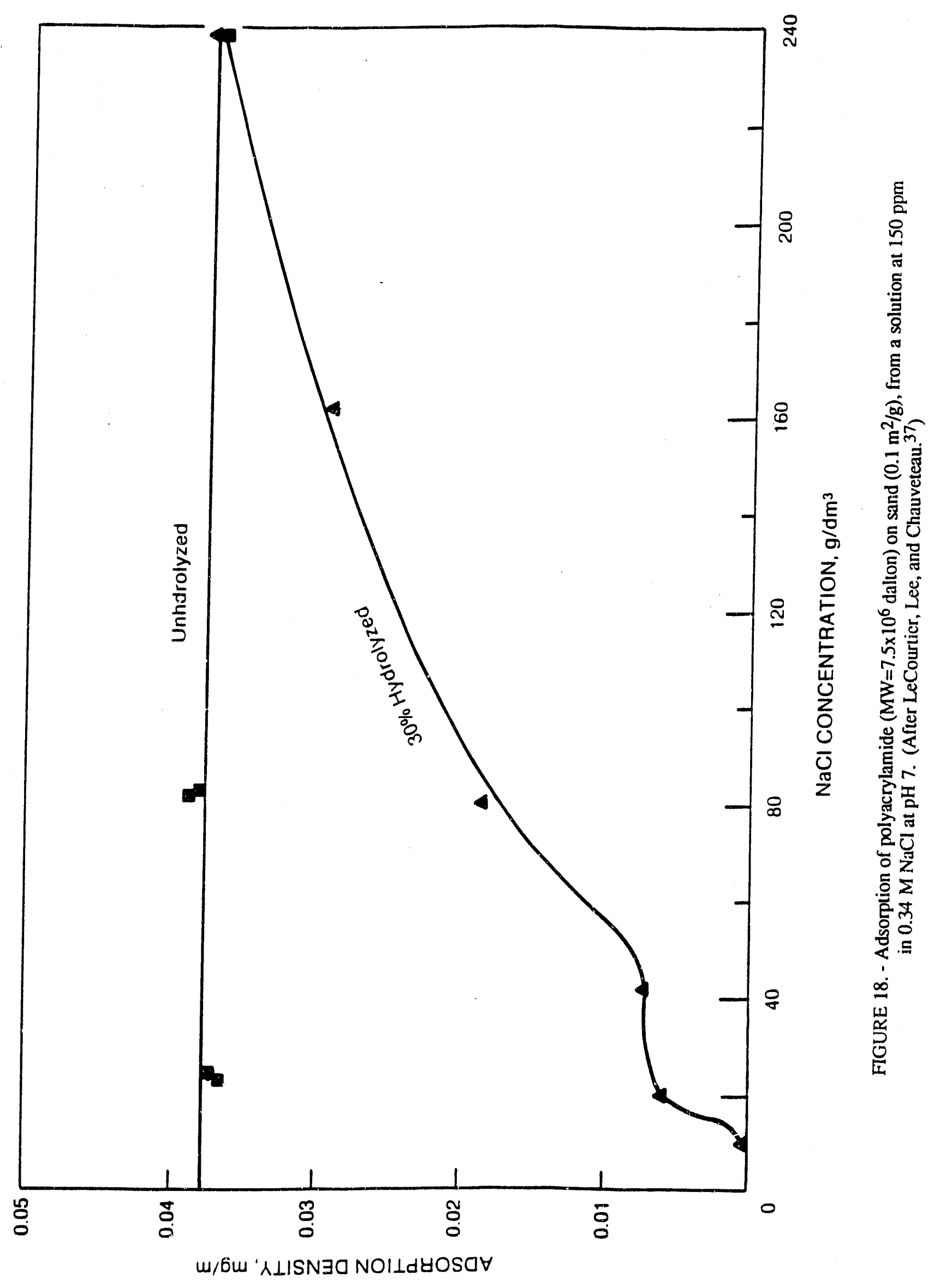




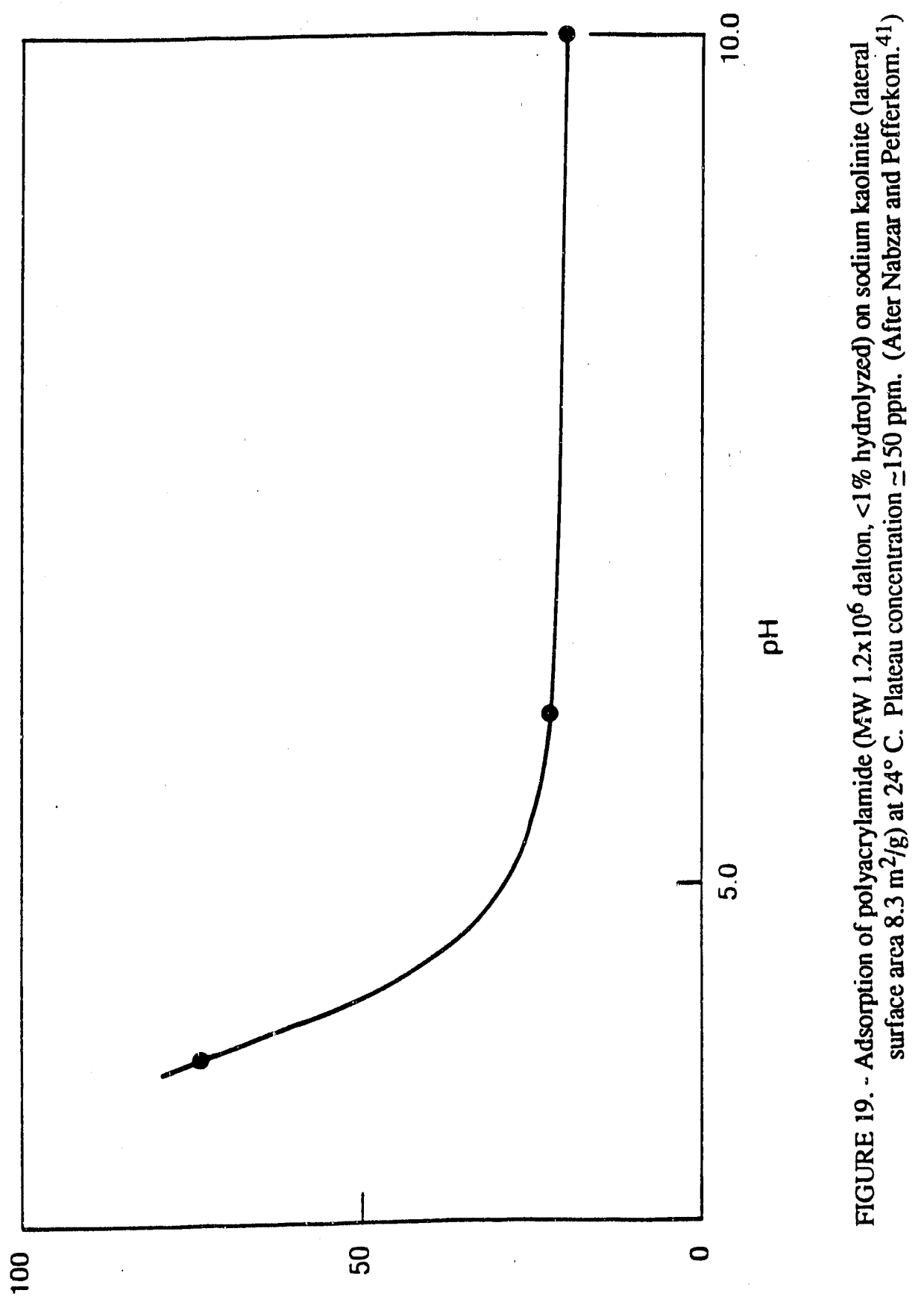

6/6س 'NOILdYOSAY 


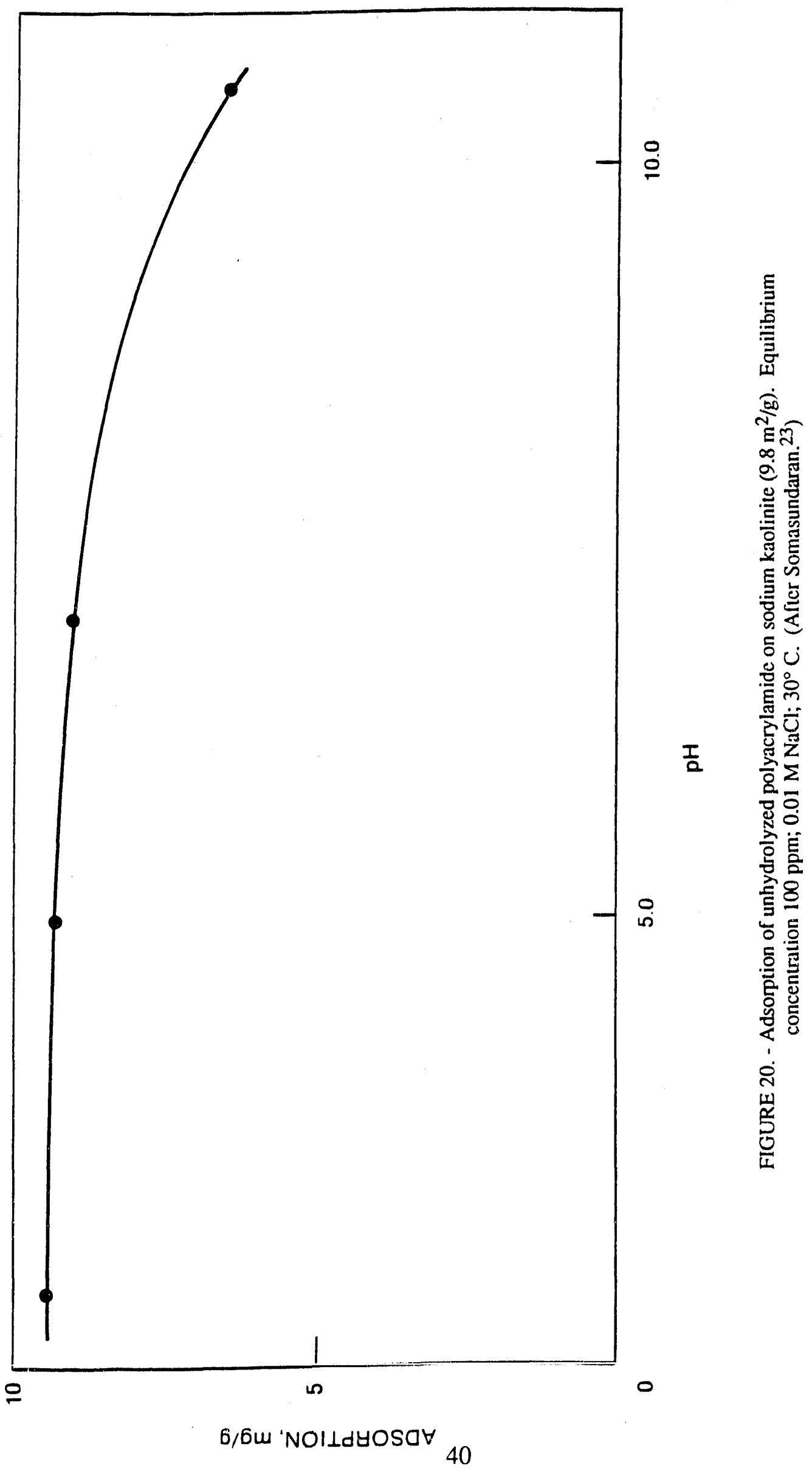




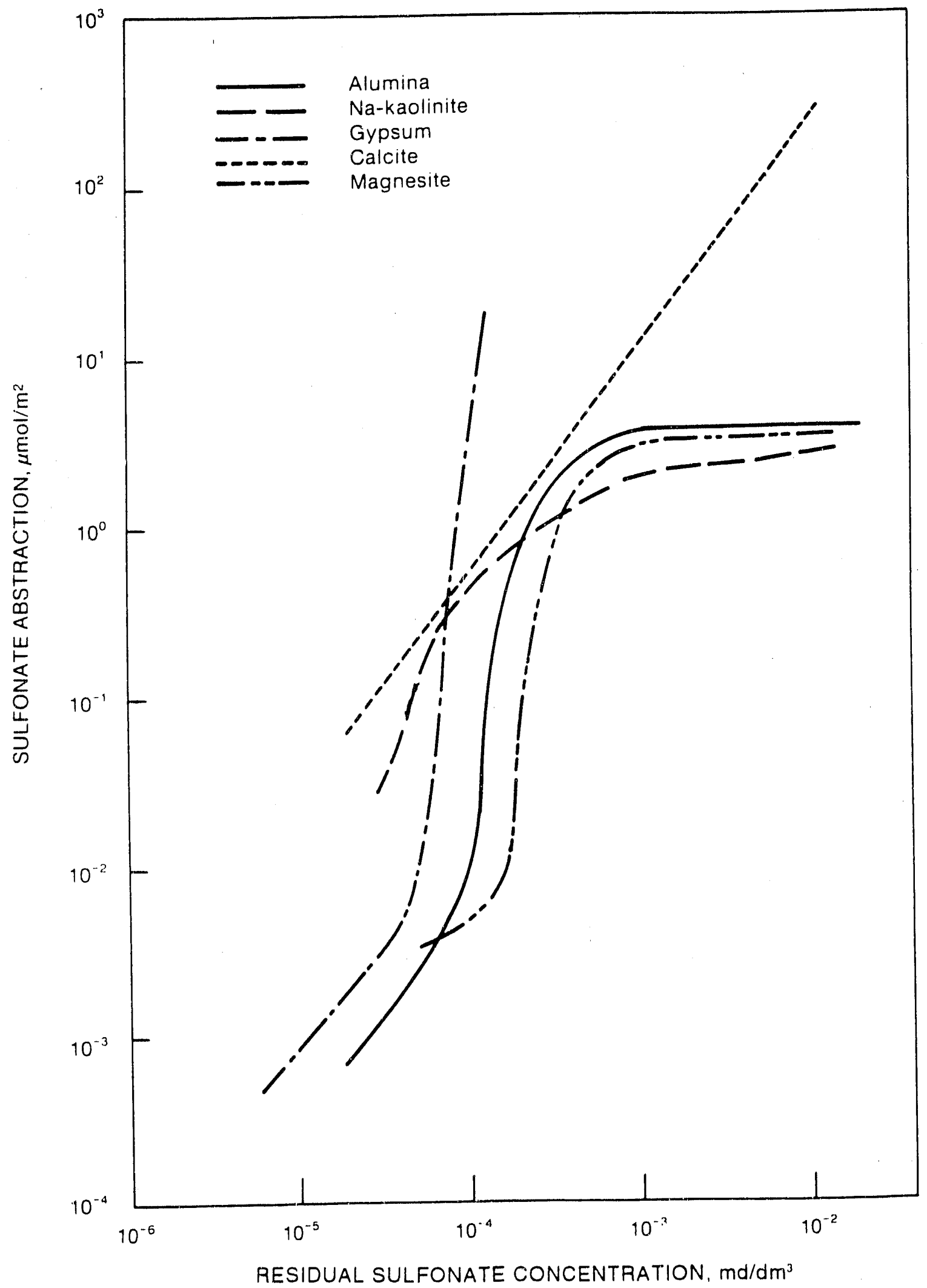

FIGURE 21. - Adsorption isotherms for sodium $n$-decylbenzene sulfonate on various minerals. $S / L=1 / 10,1 / 5$; $57^{\circ} \mathrm{C} ; 0.1 \mathrm{M} \mathrm{NaCl}$; natural pH. (After Somasundaran and Gryte. ${ }^{16}$ ) 


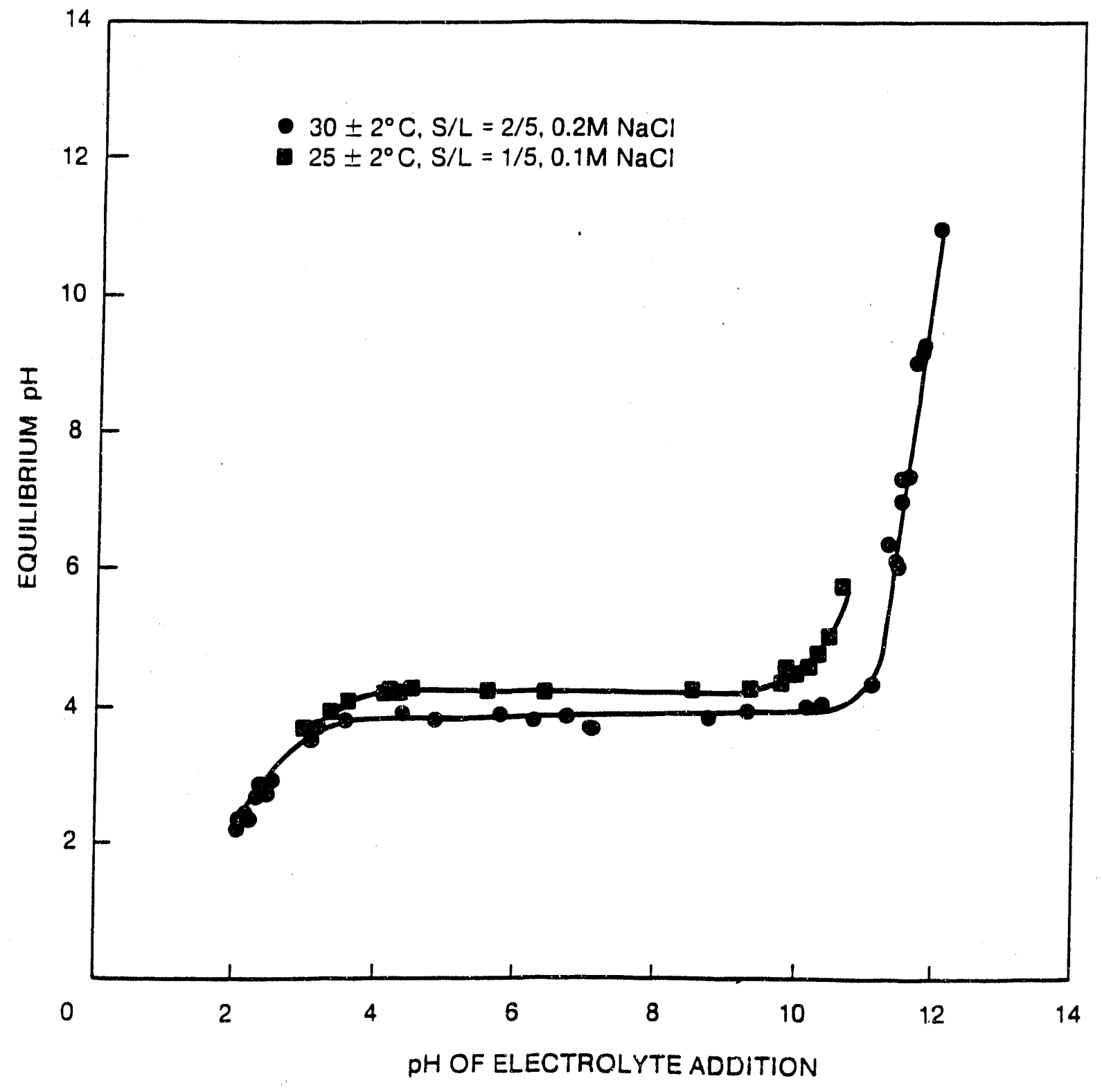

FIGURE 22. - Equilibrium pH obtained by contacting sodium kaolinite with pH-adjusted solutions of sodium chloride. (After Somasundaran. ${ }^{48}$ ) 


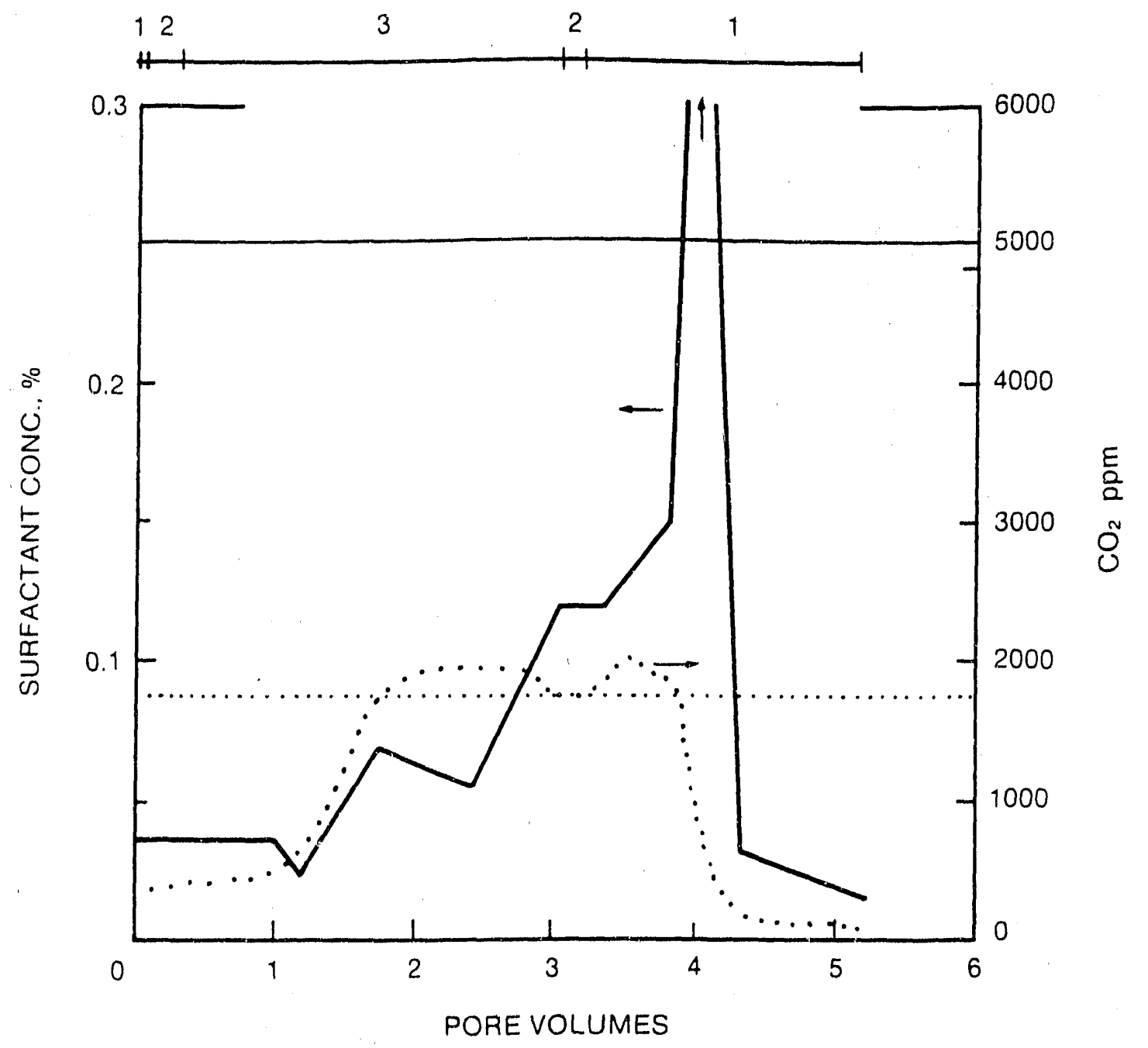

FIGURE 23. - Effluent profiles in a dilute surfactant flood enhanced by sodium carbonate (no oil) in Berea cores (2 in. $x 1 \mathrm{ft}) .1$ = hard brine $(1,920 \mathrm{ppm} \mathrm{Ca}) ; 2=$ saline preflush/postflush $(0.017 \mathrm{M} \mathrm{NaCl}) ; 3=$ surfactant-alkaline slug: injection concentrations shown by horizontal lines.(After Krumrine and Falcone. ${ }^{11}$ ) 


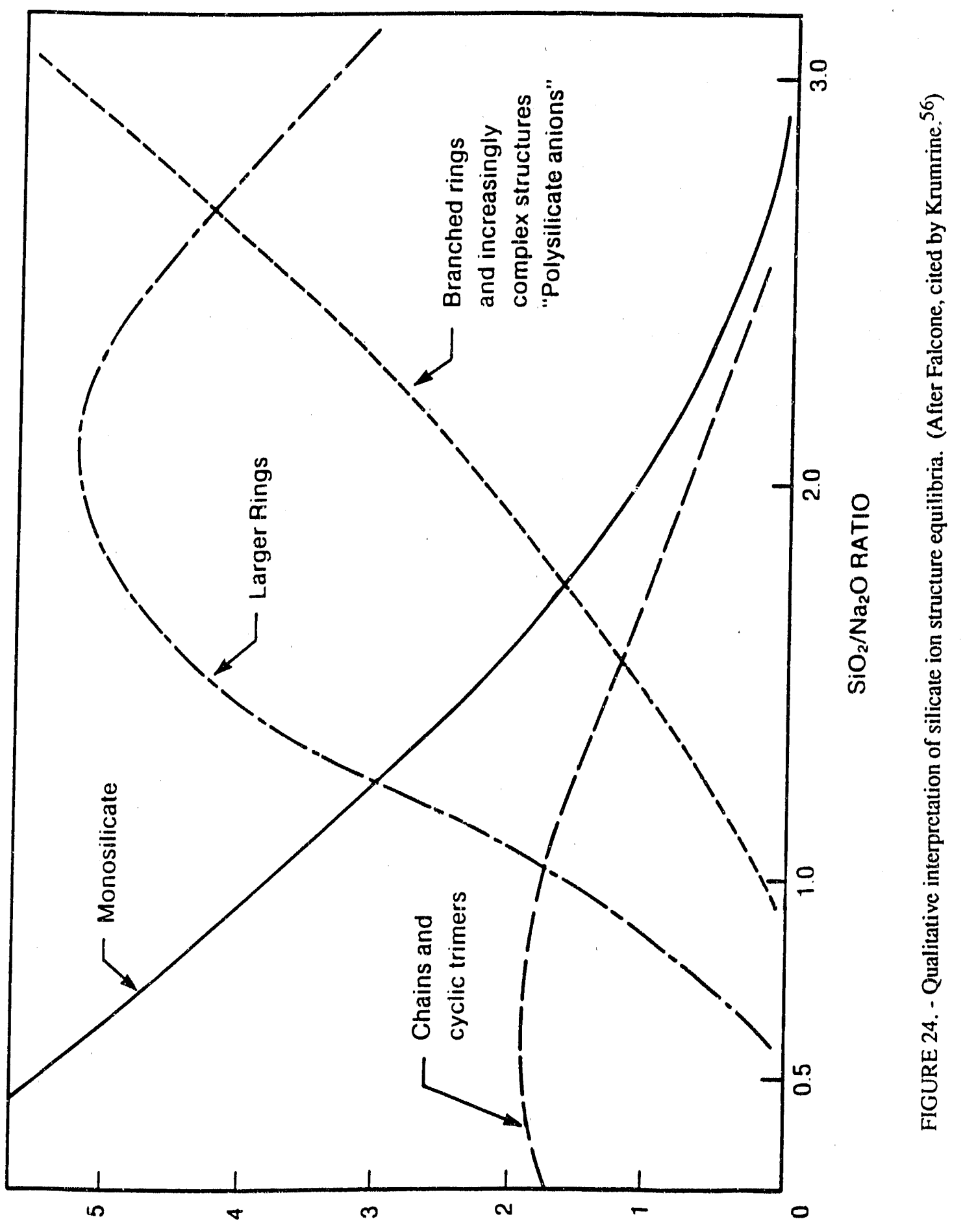

$\wedge \perp I S N \exists \perp N I Y \forall \exists d \exists \wedge I \perp \forall 7 \exists \forall \forall W N$ 


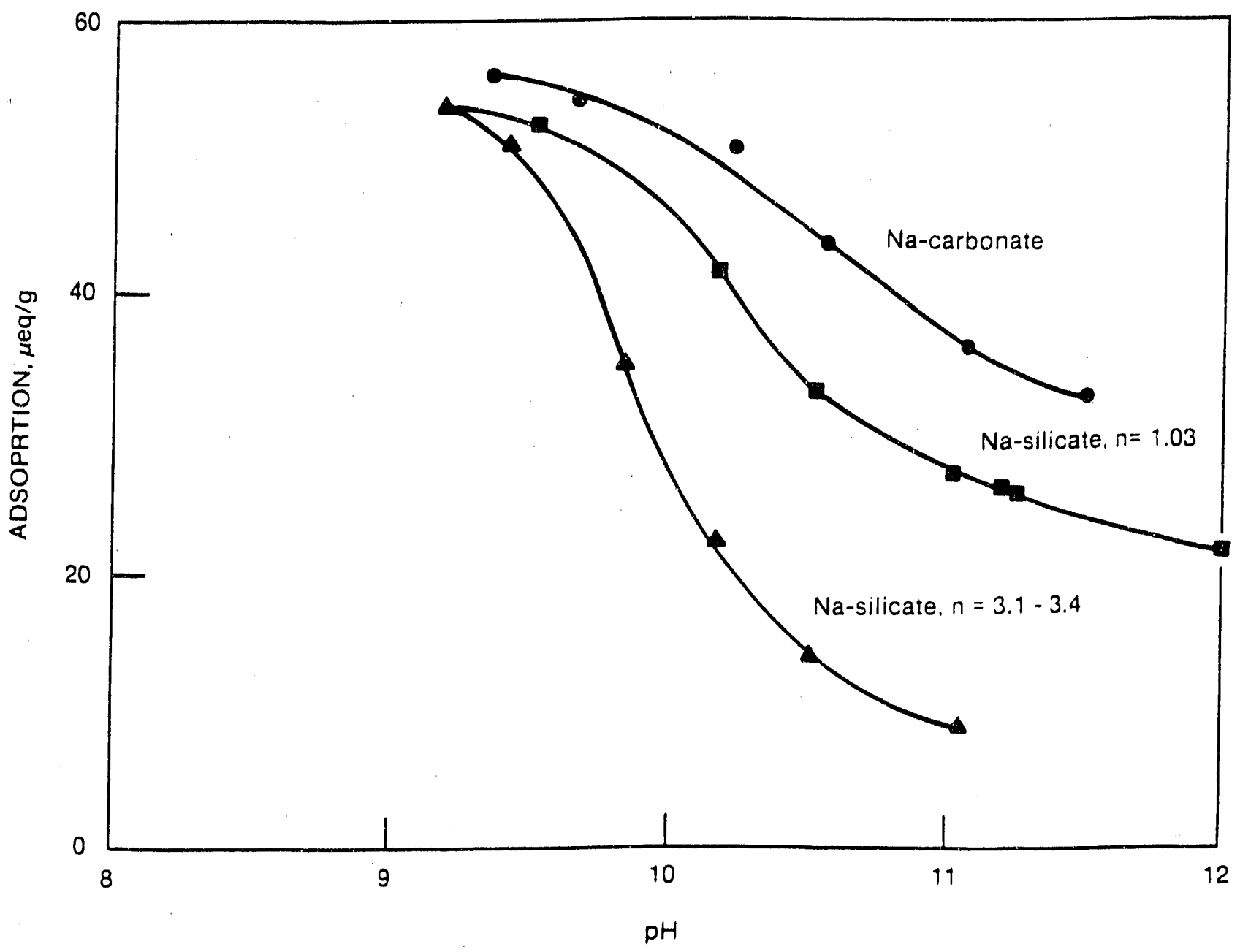

FIGURE 25. - Adsorption as a function of $\mathrm{pH}$ with various alkalis. Sodium dodecylbenzene sulfonate on kaolinite. (After Yang and Han. ${ }^{52}$ ) The exact experimental conditions are not clear. 


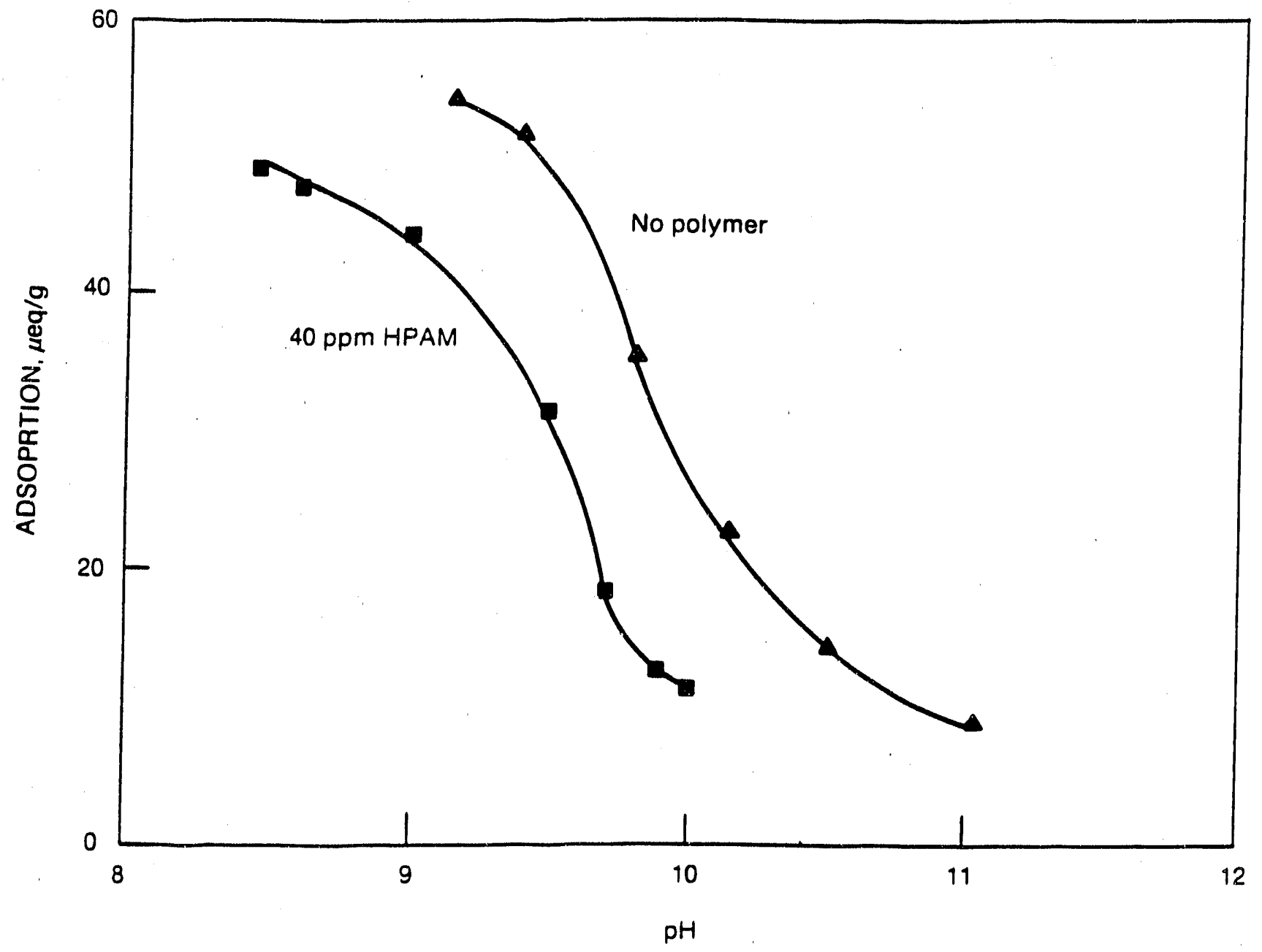

FIGURE 26. - The effect of partly hydrolyzed polyacrylamide, $40 \mathrm{ppm}$, on the adsorption isotherms for $\mathrm{n}+3$ silicate of figure 25. (After Yang and Han. ${ }^{52}$ ) 


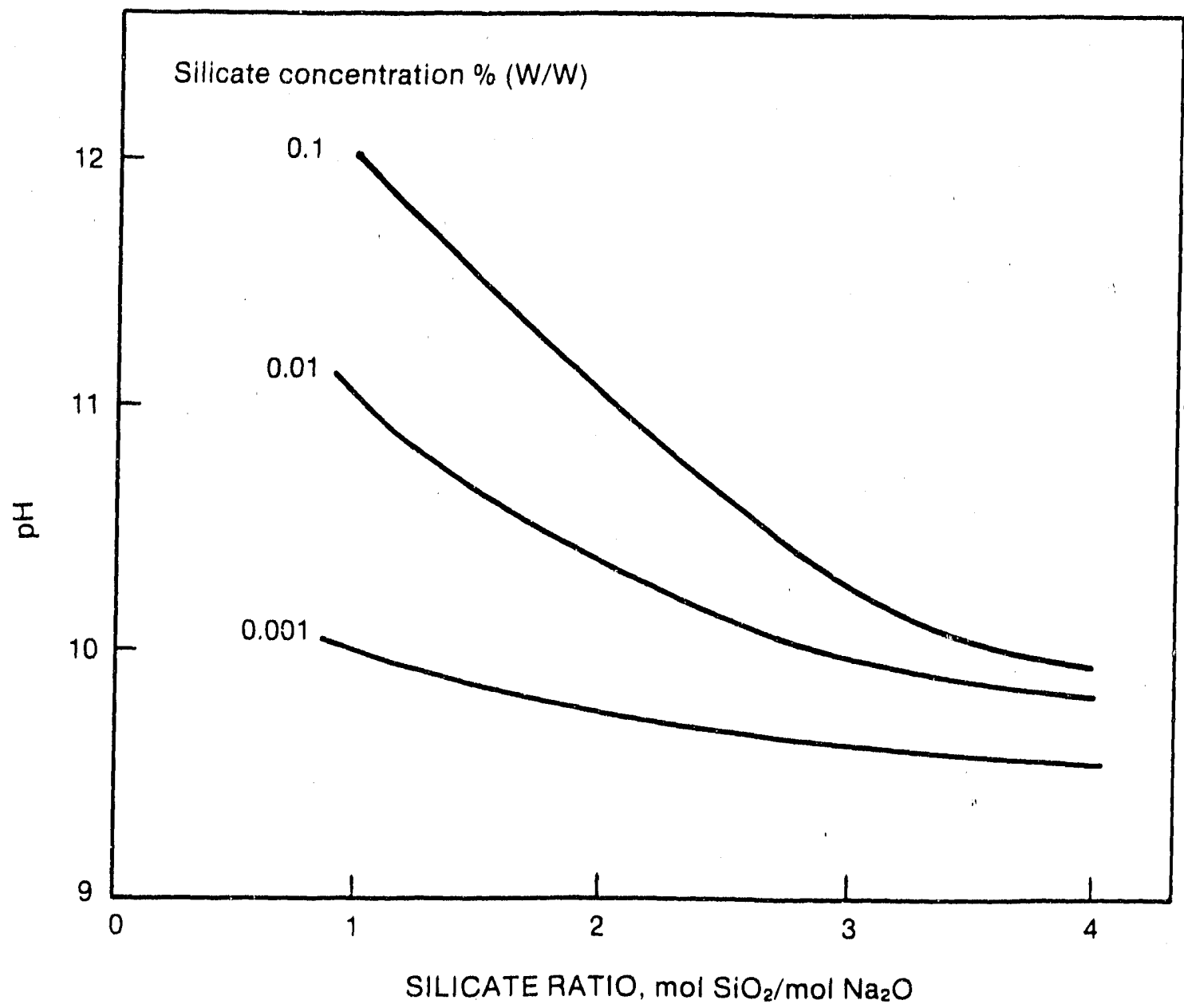

FIGURE 27. - pH values for silicate solutions of different concentrations and silicate ratios. (After Krumrine and Falcone. ${ }^{60}$ ) 


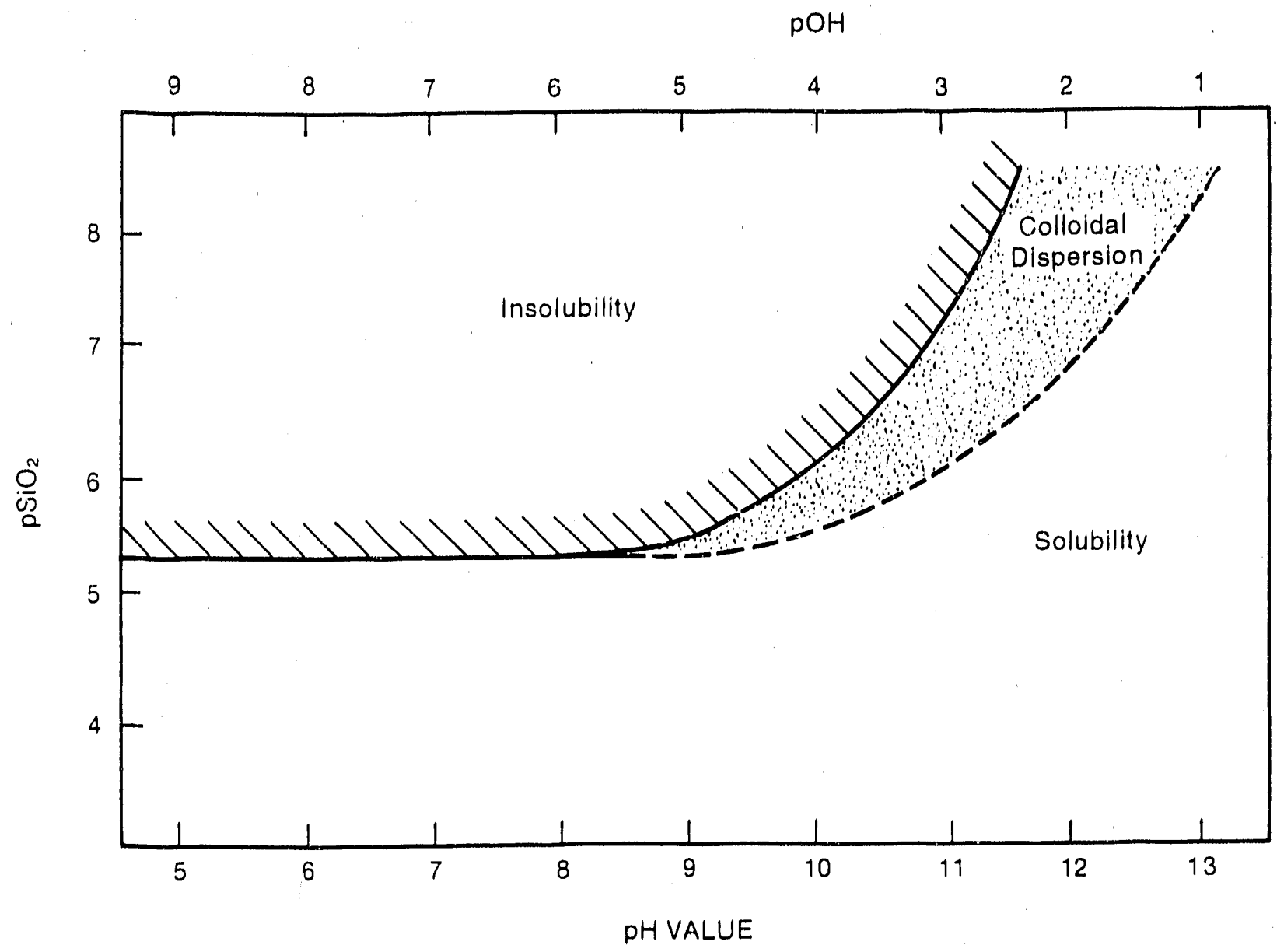

FIGURE 28. - Domains of solubility, colloidal dispersion, and insolubility for silicates. (After Krenrine and Falcone. ${ }^{60}$ ) 

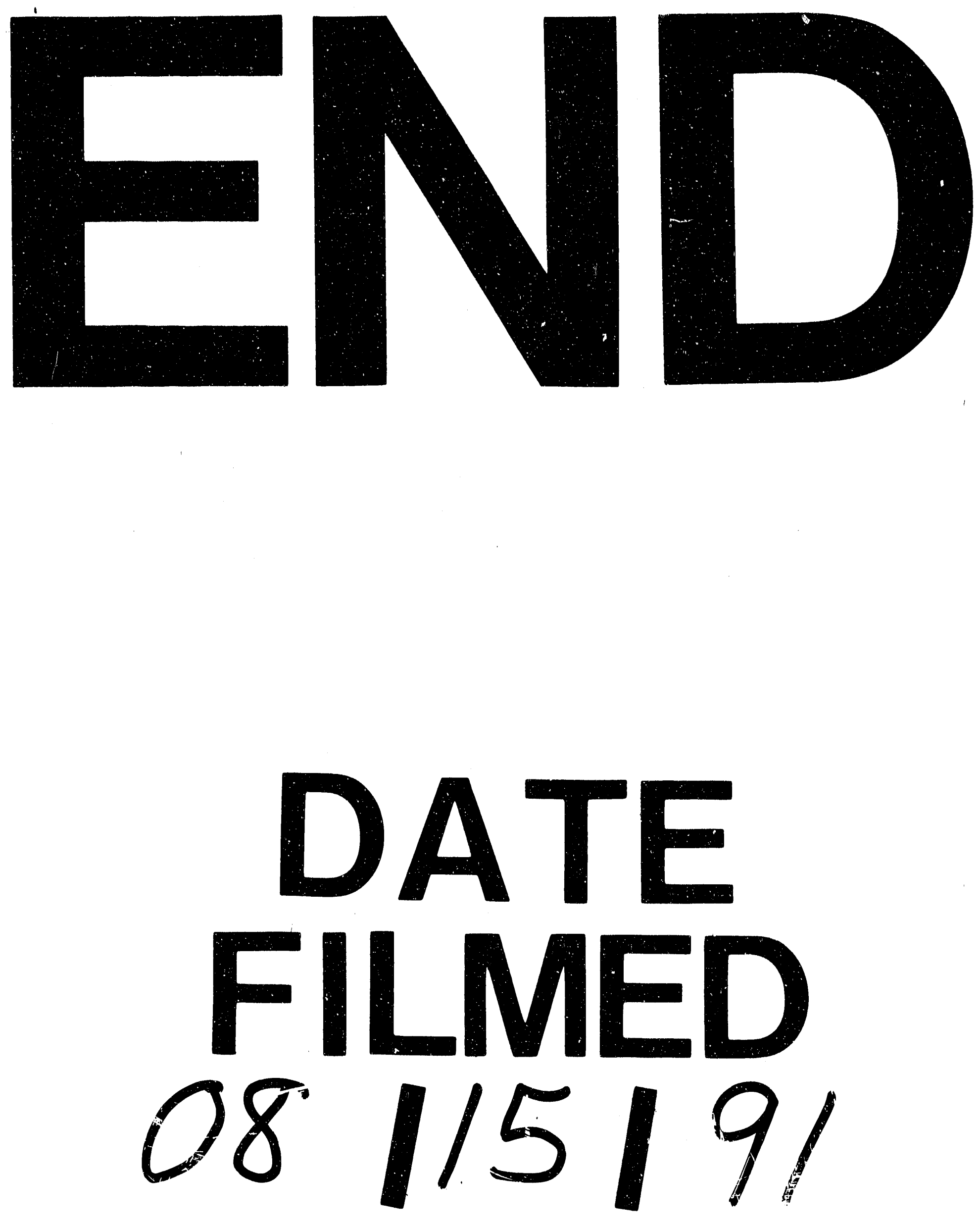
